\title{
Sizilien und Kalabrien - Binnendifferenzierung im Regno?
}

\author{
JOCHEN JOHRENDT
}

Rudolf Schieffer zum 31. Januar 2012

Seit der 1091 endgültig abgeschlossenen Eroberung Siziliens durch den Großgrafen Roger, der zuvor allein über den südlichen Teil Kalabriens geherrscht hatte, waren der Sporn des Stiefels und die Insel Sizilien unter einer Herrschaft zusammengefasst ${ }^{1}$. Unter Roger II. traten in den 20er Jahren des 12. Jahrhunderts auch die nördlichen Teile Kalabriens zu diesem Herrschaftskomplex dazu ${ }^{2}$. Als Raum war nun nicht nur die Region Kalabrien vereint, sondern ab diesem Zeitpunkt unterstanden Sizilien und Kalabrien ein und demselben Herrscher, seit der Erhebung Rogers II. zum König von Sizilien durch Anaklet II. im Jahre 1130 einem König3. Doch trotz dieser herrschaftlichen Vereinigung vollzog

1 Vgl. zur Eroberung durch Roger I. jüngst Julia BECKER: Graf Roger I. von Sizilien. Wegbereiter des normannischen Königreichs, Tübingen 2008 (Bibliothek des Deutschen Historischen Instituts in Rom 117), dort die neuere Literatur bequem zusammengestellt, hervorgehoben sei vor allem Graham A. LOUD: The Age of Robert Guiscard. Southern Italy and the Norman Conquest, Harlow 2000 (The Medieval World), S. 146-185. Wenig weiterführend und ohne Bezug auf außeritalienische Forschungen jüngst auch Pasquale HAMEL: L'Invenzione del regno dalla conquista normanna alla fondazione del Regnum Siciliae (1061-1154), Palermo 2009 (Augustali/Pocket 1); zur Errichtung der lateinischen Bistümer auf Sizilien immer noch Erich CASPAR: Die Gründungsurkunden der sicilischen Bistümer und die Kirchenpolitik Graf Rogers I. (1082-1098), Innsbruck 1902. Zur Herrschaft Rogers I. auf Sizilien und in Kalabrien vgl. ferner BECKER: Graf S. 162-168; sowie DIES.: La politica Calabrese dei primi conti Normanni dopo la conquista della Sicilia (1080-1130), in: Archivio storico per la Calabria e la Lucania 73 (2006) S. 47-70, hier S. 49-54; DIES.: Un dominio tra tre culture. La contea di Ruggero I alla fine dell'XI secolo, in: QFIAB 88 (2008) S. 1-33.

2 Vgl. dazu die Bemerkungen bei Jochen JohrendT: Der Sonderfall vor der Haustüre: Kalabrien und das Papsttum, in: Römisches Zentrum und kirchliche Peripherie. Das universale Papsttum als Bezugspunkt der Kirchen von den Reformpäpsten bis zu Innozenz III., hg. v. Jochen JOHRENDT/Harald MülleR, Berlin/New York 2008 (Neue AAG 2), S. 235-258, hier S. 239.

3 Vgl. vor allem Hubert Houben: Roger II. von Sizilien. Herrscher zwischen Orient und Okzident, Darmstadt ${ }^{2} 2010$ (Gestalten des Mittelalters und der Renaissance), dort auch eine aktualisierte Literaturliste auf dem Stand von 2009. Zu Kalabrien als Untersuchungsregion vgl. auch Pietro DALENA: La Calabria in età normanna: aspetti e pro- 
sich die Entwicklung in den beiden Regionen, die im Folgenden miteinander verglichen werden ${ }^{4}$, nicht gleichartig. Obwohl sie unter einem Herrscher zusammengefasst waren, bewahrten beziehungsweise entwickelten sie Eigenheiten, die sie von einander unterschieden - auch im Verhältnis der Ortskirchen zu Rom ${ }^{5}$.

Die Insel Sizilien bietet sich als eigenständige Region bereits durch ihren geographischen Charakter als Insel $\mathrm{an}^{6}$. Sizilien und Kalabrien haben insofern im Regno eine Sonderstellung, als sie die Ausgangsbasis für die durch Roger II. fortgeführte Expansion bildeten ${ }^{7}$. Der besondere Reiz eines Vergleiches beider Landschaften im Hinblick auf ihre Ausrichtung auf Rom hin besteht vor allem darin, dass die beiden Regionen im 12. Jahrhundert herrschaftlich zusammengefasst waren, hinsichtlich der kirchlichen Kompetenzen der Herrscher jedoch aus der Perspektive der Päpste unterschiedliche Rahmenbedingungen galten. Waren die normannischen Herrscher darum bemüht, in der Nachfolge Rogers I. das diesem 1098 von Urban II. übertragene Recht der apostolischen Legation zu verstetigen und auch auf die Terraferma auszudehnen, was ihnen im Vertrag von Benevent (1156) mit Modifikationen auch gelang ${ }^{8}$, so waren die

blemi, in: Mezzogiono - Federico II - Mezzogiorno. Atti del Convegno internazionale di Studio promosso dall'Istituto Internazionale di Studi Federiciani, Consiglio Nazionale delle Ricerche, Potenza - Avigliano - Castel Lagopesole - Melfi, 18-23 ottobre 1994, a cura di Cosimo Damiano FonseCA, 2 Bde., Roma 1999, Bd. 1 S. 343379, zur kirchlichen Struktur Kalabriens S. 365-379.

4 Dabei können die folgenden Ausführungen auf bereits publizierte Ergebnisse des Netzwerkes zur Region Kalabrien bis zum Jahr 1198 aufbauen, vgl. JOHRENDT: Sonderfall (wie Anm. 2). Für wertvolle Hinweise zu dieser 2008 erschienen Arbeit, die in den Kalabrien und Sizilien vergleichenden Beitrag einfließen, danke ich Rudolf Hiestand und Hubert Houben.

5 Vgl. jüngst zur lateinischen unteritalienischen Kirche Graham A. LOUD: The Latin Church in Norman Italy, Cambridge 2007.

6 Zur Charakterisierung Kalabriens als Untersuchungseinheit vgl. JOHRENDT: Sonderfall (wie Anm. 2) S. 239.

7 Houben: Roger II. (wie Anm. 3) S. 32-43.

8 Zur apostolischen Legation für Roger I. nach wie vor grundlegend Josef DEÉR: Der Anspruch der Herrscher des 12. Jahrhunderts auf die apostolische Legation, in: AHP 2 (1964) S. 117-186 (Wiederabdr. in: Byzanz und das abendländische Herrschertum. Ausgewählte Aufsätze von Josef Deér, hg. v. Peter ClASSEN, Sigmaringen 1977 [VuF 21], S. 439-494), hier S. 118-142 (439-460); BeCKER: Graf (wie Anm. 1) S. 145, geht davon aus, dass die Verleihung von Anfang an erblich war, was sich mit der Interpretation der normannischen Herrscher deckt, vermutlich jedoch nicht mit der päpstlichen Interpretation der Vergabe. Als erblich wurde die apostolische Legation der sizilischen Herrscher erst durch den Vertrag von Benevent im Jahre 1156 festgeschrieben. Edition bei Constitutiones et acta publica imperatorum et regum inde ab a. DCCCCXI usque ad a. MCXCVII (911-1197), hg. v. Ludwig WeILAND, Hannover 1893 (MGH Const. 1), Nr. 413 S. 588-590. Legationen nach und Appellationen von Sizilien aus blieben nach dieser Regelung untersagt, vgl. dazu auch Horst ENZENSBERGER: Der „böse“ und der 
Päpste stets um eine Zurückdrängung der Rechte der sizilischen Könige bemüht. Doch erst am Ende des 12. Jahrhunderts, unter Cölestin III., waren die Bemühungen im Zuge der Wirren nach dem Tod Wilhelms II. vor allem hinsichtlich der Bischofseinsetzung von Erfolg gekrönt ${ }^{9}$. Das gilt grosso modo auch für den Beginn der Herrschaft Friedrichs II. unter der Vormundschaft Innozenz' III. - auch wenn der Papst sich im Januar 1209, unmittelbar nach dem eigenständigen Herrschaftsantritt des Staufers am 26. Dezember 1208, bei diesem beklagte, dass Friedrich die dem sizilischen König zugestandenen Rechte über die Kirche Unteritaliens zu großzügig auslege ${ }^{10}$. Berühmt ist das oft zitierte Diktum Johannes von Salisburys, dass Wilhelm II. more tirannorum

„gute" Wilhelm. Zur Kirchenpolitik der normannischen Könige von Sizilien nach dem Vertrag von Benevent (1156), in: DA 36 (1980) S. 385-432, hier S. 399-402.

9 Nach dem Tode Wilhelms II. beanspruchten bekanntlich Constanze, die Gattin Kaiser Heinrichs VI. und Tankred von Lecce die sizilische Krone, zu den Ereignissen vgl. Annkristin SCHLICHTE: Der ,gute“ König. Wilhelm II. von Sizilien (1166-1189), Tübingen 2005 (Bibliothek des Deutschen Historischen Instituts in Rom 110), S. 319326. Tankred war um Unterstützung durch den Papst bemüht und war als Gegenleistung dafür bereit, auf die Ausübung der apostolischen Legation zu verzichten, vgl. Christoph ReISINGER: Tankred von Lecce. Normannischer König von Sizilien 11901194, Köln u. a. 1992 (Kölner Historische Abhandlungen 38), S. 247-250; sowie Pier Fausto PALUMBO: Tancredi conte di Lecce e re di Sicilia e il tramonto dell'età normanna, Roma 1991 (Istituto per la storia del Mezzogiorno, Biblioteca 2), S. 211f.; die Vereinbarung zwischen Tankred und Cölestin III. findet sich ediert bei MGH Const. 1 Nr. 417 S. 593f. Zu den päpstlichen Zielen vgl. Werner MALECZEK: Ecclesiae patrimonium speciale. Sizilien in der päpstlichen Politik des ausgehenden 12. Jahrhunderts, in: Die Staufer im Süden. Sizilien und das Reich, hg. v. Theo KöLzER, Sigmaringen 1996, S. 29-42, hier S. 37-41. Zusammenfassend bereits DEÉR: Anspruch (wie Anm. 8) S. 118-139 (439- 457); DERS.: Papsttum und Normannen. Untersuchungen zu ihren lehnsrechtlichen und kirchenpolitischen Beziehungen, Köln u. a. 1972 (Studien und Quellen zur Welt Kaiser Friedrichs II. 1), S. 261-265. Die Politik der Kurie gegenüber dem Königreich Sizilien ist auch in Zusammenhang mit einem seit Alexander III. forcierten Ausbau der Herrschaft über den Kirchenstaat zu sehen, der an seiner südlichen Grenze direkt an das Regno angrenzte. $\mathrm{Zu}$ den Bestrebungen unter Cölestin III. vgl. zuletzt Brenda BOLTON: Celestine III and the Defence of the Patrimony, in: Pope Celestine III (11911198). Diplomat and Pastor, ed. by John Doran/Damian J. SMITH (Church Faith and Culture in the Medieval West), Aldershot u. a. 2008, S. 317-353.

10 Vgl. Reg. Inn. III., XI/203 vom 9. Januar 1209. Innozenz III. nimmt darin explizit auf die Zugeständnisse der Kaiserin Konstanze Bezug und ermahnt deren Sohn, sich an diese zu halten. Der konkrete Anlass für das Mahnschreiben des Papstes war der Versuch Friedrichs II., auf die avisierte Wahl des neuen Erzbischofs von Palermo Einfluss auszuüben. Zwar ist nicht klar, wie die Auseinandersetzung zwischen Innozenz III. und Friedrich II. in diesem Punkte endete, doch blieb der Palermitaner Erzstuhl offenbar bis zum Januar 1211 vakant, vgl. Norbert KAMP: Kirche und Monarchie im staufischen Königreich Sizilien, 3 Bde., München 1973-1982 (Münstersche MittelalterSchriften 10/I,1-4), Bd. 3 S. 1127. Zur Sache vgl. auch Gerhard BAAKEN: Ius imperii ad regnum. Königreich Sizilien, Imperium Romanum und römisches Papsttum vom Tode Kaiser Heinrichs VI. bis zu den Verzichterklärungen Rudolfs von Habsburg, Köln u. a. 1993 (Beih. RI 11), S. 177-181. 
über seine Kirche geherrscht habe ${ }^{11}$, was die moderne Forschung bisweilen mit einem straffen Kirchenregiment umschrieben hat, bei dem die unteritalienischen Herrscher jedoch nicht alleine standen ${ }^{12}$.

Für die Zusammenarbeit der traditionell stark auf den König ausgerichteten unteritalienischen Kirche mit Rom bildete die Vormundschaftsregierung Innozenz' III. ohne Frage einen deutlichen Einschnitt. Kaiserin Konstanze hatte dem Papst in ihrem Testament die Vormundschaft für Friedrich II. übertragen ${ }^{13}$. Und als sie am 27. November 1198 noch vor dem vierten Geburtstag des kleinen Friedrich II. starb, trat diese Regelung in Kraft. Der formale Lehnsherr des Königreichs Sizilien wurde dadurch zum Vormund des minderjährigen Königs. Innozenz III. nahm diese Vormundschaft aktiv wahr und griff gestaltend in die unteritalienischen Verhältnisse ein, wobei die Auseinandersetzung mit Markward von Annweiler nur die Spitze des Eisberges darstellt ${ }^{14}$, bei

11 The Historia pontificalis of John of Salisbury, ed. and transl. by Marjorie CHIBNALL, Oxford 1986 (Oxford Medieval Texts), c. 32 S. 65; vgl. dazu auch LOUD: Latin Church (wie Anm. 5) S. 255-258.

12 Dass sich bei der Besetzung der Bistümer und beim Kirchenregiment eine ähnlich dominante königliche Position auch in anderen Landeskirchen finden lässt, betont etwa Graham A. LouD: Royal Control of the Church in the Twelfth-Century Kingdom of Sicily, in: Studies in Church History 18 (1982) S. 147-159, hier S. 148f.; Wiederabdr. in: DERS.: Conquerors and Churchman in Norman Italy (Variourm Collected Studies Series), Aldershot 1999, X S. 147-159, hier S. $148 f$.

13 Das Testament ist als Text nicht überliefert, vgl. dazu auch die Bemerkungen bei MDH Dep. Ks. 71, dort die Zusammenstellung der Überlieferung. Am ausführlichsten berichten über das Testament die "Gesta Innocentii", Edition bei The Gesta Innocentii III. Text, introduction and commentary by David GRESS-WRIGHT, Ann Arbor 2000, S. 19f. Die Darstellungen der Gesta Innocentii sind nicht immer eindeutig, vgl. jüngst am Beispiel der bisher als Testament Heinrichs VI. interpretierten Passage der "Gesta Innocentii», Matthias THUMSER: Letzter Wille? Das höchste Angebot Kaiser Heinrichs VI. an die römische Kurie, in: DA 62 (2006) S. 85-133. Dass die «Gesta Innocentii» auch ein gegen Markward von Annweiler gerichtetes Werk waren, hat deutlich betont Brenda Bolton: To important to Neglect: The Gesta Innocentii PP III, in: Church and Chronicle in the Middle Ages. Essay presented to John Taylor, hg. v. Ian WoOD/Graham A. Loud, London/Rio Grande 1991, S. 87-99. Eine kritische Edition mit einem angemessenen Sachapparat fehlt trotz der Vorarbeiten von Gress-Wright und der großen Bedeutung Innozenz' III. für die Geschichte Europas bis heute. Jüngst versuchte Giulia BARONE: I Gesta Innocentii III: politica e cultura a Roma all'inizio del Duecento, in: Studi sul Medioevo per Girolamo Arnaldi, hg. v. Giulia Barone/ Lidia CAPO/Stefano GASPARRI, Roma 2001, S. 1-23, Kardinaldiakon Johannes von S. Maria in Cosmedin als Autor der Gesta namhaft zu machen.

14 Vgl. Nach wie vor grundlegend für die Tätigkeit Innozenz III. auf Sizilien Friedrich BAETHGen: Die Regentschaft Papst Innozenz III. im Königreich Sizilien, Heidelberg 1914 (Heidelberger Abhandlungen zur mittleren und neueren Geschichte 44); Wolfgang STÜRNER: Friedrich II., Darmstadt ${ }^{3} 2009$ (Gestalten des Mittelalters und der Renaissance), S. 85-105; BAAKEN: Ius (wie Anm. 10) S. 171-177; substanziell wenig darüber hinaus gehend die Ausführungen bei John C. MoORE: Pope Innocent III (1160/61-1216). To root up and to plant, Leiden u. a. 2003 (The medieval Mediter- 
der er Heere aufbot, um sein Mündel Friedrich von Sizilien zu schützen, und den Widerstand gegen Markward organisierte - auch wenn seine Bemühungen nicht immer von Erfolg gekrönt waren ${ }^{15}$.

Dennoch lässt der neue Impetus der päpstlichen Unteritalienpolitik einen engeren Kontakt zu den Kirchen Unteritaliens erwarten, als dies zuvor der Fall war, der sich auch in der Quantität der Urkunden widerspiegeln müsste. Hinzu kommt noch eine mit dem Pontifikat Innozenz' III. veränderte Überlieferungssituation. Das Epochenjahr 1198 ist für Unteritalien folglich ein doppelter Einschnitt. Denn anders als zuvor können wir nach 1198 - dank der Registerüberlieferung, die uns für den Untersuchungszeitraum abgesehen vom Register Gregors VII. vor Innozenz III. fehlt ${ }^{16}$ - in wesentlich stärkerem Maße das Wollen des Papstes fassen. Denn dieses kommt in der Regel in Mandaten, in Aufträgen zum Ausdruck, die aufgrund ihrer Zeitgebundenheit in den Empfängerarchiven bekanntlich eine geringe Überlieferungschance haben ${ }^{17}$. Durch

ranean 47), S. 65-68; oder Helene TillmanN: Papst Innocenz III., Bonn 1954 (Bonner Historische Forschungen 3), S. 111-117. Einen Überblick über die Situation im Königreich Sizilien während der Minderjährigkeit Friedrichs II. bietet auch Ronald NeUmanN: Parteibildungen im Königreich Sizilien während der Unmündigkeit Friedrichs II. (1198-1208), Frankfurt a. M. u. a. 1986 (Europäische Hochschulschriften III/266), S. 17-37. Zu Markward von Annweiler und dessen Wirken nach dem Tod Heinrichs VI. vgl. Jan KeUPP: Dienst und Verdienst. Die Ministerialen Friedrich Barbarossas und Heinrichs VI., Stuttgart 2002 (Monographien zur Geschichte des Mittelalters 48), S. 280-285.

15 Vgl. etwa die lapidare Feststellung von STÜRNER: Friedrich II. (wie Anm. 14) S. 104: „Es verwundert angesichts der Verhältnisse im Regnum Sicilie sicher niemanden, dass die Verfügungen des Papstes offenbar kaum Beachtung fanden."

$16 \mathrm{Zu}$ den päpstlichen Registern vor Innozenz III. vgl. jüngst Rudolf SCHIEFFER: Die päpstlichen Register vor 1198, in: Das Papsttum und das vielgestaltige Italien. Hundert Jahre Italia Pontificia, hg. v. Klaus HERBERS/Jochen JOHRENDT, Berlin/New York 2009 (AAG, N. F. 5), S. 261-273.

$17 \mathrm{Vgl}$. dazu grundlegend Arnold EsCH: Überlieferungs-Chance und ÜberlieferungsZufall als methodisches Problem des Historikers, in: HZ 240 (1985) S. 529-570; entscheidend für die Überlieferung sind bei den Mandaten ebenso wie bei den Urkunden allgemein der Umgang der Empfänger mit den in ihrem Besitz befindlichen Dokumenten. Das gilt auch für die Überlieferung der Urkunden von Gegenpäpsten. Vorstellungen von einer ,systematische[n] Kassierung des Großteils der urkundlichen Überlieferung gegenpäpstlicher Obödienz post scisma", die nach dem Willen der Kurie vollzogen worden sei, suggerieren einen alles beherrschenden Apparat, der sogar die Überlieferung einzelner Urkunden kontrollieren könnte, so jüngst Kai-Michael SPRENGER: Damnatio memoriae oder Damnatio in memoria? Überlegungen zum Umgang mit so genannten Gegenpäpsten als methodisches Problem der Papstgeschichtsschreibung, in: QFIAB 89 (2009) S. 31-62, Zitat S. 52. In das Bild einer systematischen Kassierung wollen auch die überlieferten Originalurkunden Anaklets II. in Unteritalien nicht passen. Bekanntlich bemühte sich Bonifaz VIII., der über einen weitaus besser ausgebauten Kurienapparat verfügte als die Päpste des 12. Jahrhundert, gezielt um die Rückrufung einzelner Urkunden seines Vorgängers Cölestin V., so etwa des Plenarablasses für S. Maria di Collemaggio, vgl. dazu Reg. Bon. VIII., Nr. 332 u. 815f. 
die mit Innozenz III. einsetzende kontinuierliche Überlieferung der Papstregister wandelt sich die so beschriebene Überlieferungssituation, auch wenn lediglich bis zu 20 Prozent der ausgestellten Urkunden in die Register eingetragen worden sein dürften ${ }^{18}$.

Blättert man die bis zum Registerband 11 für das Pontifikatsjahr 1208/1209 vorgedrungenen Bände der Edition der Register Innozenz III. durch $^{19}$, so vermittelt der erste Eindruck eine schlagartig gesteigerte Intensivierung der Kontakte zwischen Rom und den Kirchen in Kalabrien und Sizilien. Denn nicht weniger als 87 Stücke sind den Registern zu entnehmen ${ }^{20}$. Das ist

Doch die Interventionen Bonifaz' VIII. zeigten keinen Erfolg, vgl. dazu Michele MACCARRONE: L'indulgenza del Giubileo del 1300 e la basilica di S. Pietro, in: Roma anno 1300. Atti della IV settimana di studi di storia dell'arte medievale dell'Università di Roma „La Sapienza“ (19-24 maggio 1980), hg. v. Nagiola Maria RomANicI, Roma 1983, S. 731-752; Wiederabdr. in: Romana Ecclesia Cathedra Petri, hg. v. Pietro ZeRBI/Raffaello VOlPINI/Alessandro GALuzZI, 2 Bde., Roma 1991 (Italia Sacra 47 u. 48), Bd. 2, S. 1157-1206, hier S. 1181; Edith PAszTOR: Celestino V e Bonifacio VIII, in: Indulgenza nel medioevo e perdonanza di papa Celestino. Atti del Convegno storico internazionale, L'Aquila, 5-6 ottobre 1984, hg. v. Alessandro ClEMENTI, L'Aquila 1987 (Convegni celestiniani 1), S. 61-78, hier S. 72. Die Urkunde ist noch heute erhalten. Insofern sollte man die Fähigkeiten der Kurie nicht überbewerten und den Akzent für die Bedingungen und die Chance der Überlieferung einzelner Urkunden nach wie vor bei den Empfängern und deren Bedürfnissen belassen. Zu den Revokationen Bonifaz' VIII. allgemein Alessandra BARTOLOMEI RomagnOLI: Le bolle di Celestino V cassate da Bonifacio VIII, in: AHP 37 (1999) S. 61-83; Tilmann SCHMIDT: Critica e revoche di documenti: il pontificato di Bonifacio VIII, un'eredità condizionante, in: Bonifacio VIII. Ideologia e azione politica. Atti del Convegno organizzato nell'ambito dlle Celebrazioni per il VII Centenario della morte, Città del Vaticano - Roma. 26-28 aprile 2004, Roma 2006 (Bonifaciana 2), S. 43-57.

$18 \mathrm{Vgl}$. dazu grundlegend die Arbeiten von Othmar HagenedeR: Probleme des päpstlichen Kirchenregiments im hohen Mittelalter (Ex certa scientia, non obstante, Registerfuihrung), in: Lectiones eruditorum extraneorum in Facultate philosophica Universitatis Carolinae Pragensis factae 4, Praha 1995, S. 49-77, hier S. 53; DERS.: Die Register Innozenz' III., in: Papst Innozenz III. Weichensteller der Geschichte Europas, hg. v. Thomas Frenz, Stuttgart 2000, S. 91-101, hier S. 92f.; sowie DERS.: Die Rechtskraft spätmittelalterlicher Papst- und Herrscherurkunden „ex certa scientia“, „non obstantibus“ und „propter importunitatem petentium“, in: Die Papsturkunde und das europäische Urkundenwesen, Studien zu ihrer formalen und rechtlichen Kohärenz vom 11. bis 15. Jahrhundert, hg. v. Peter HeRde/Hermann JAKOBS, Köln u. a. (ADipl Beih. 7), S. 401-429.

19 Die Registerbände 3 und 4 sind verschollen. Von ihnen sind allein die Rubriken überliefert, aus denen Werner Maleczek die Registerbände mit Hilfe der Empfängerüberlieferung zu rekonstruieren sucht.

20 Bei der Zählung der Stücke bin ich nach den Prinzipien der Pontificienbände verfahren, die bei einem Schreiben an mehrere Personen ein Hauptregest und entsprechende Nebenregesten anlegen. Ein analoges Vorgehen bei der Auswertung der Register ist hinsichtlich der Vergleichbarkeit der Ergebnisse der aus IP 10 gewonnenen Empfängerüberlieferung und der Registerüberlieferung notwendig. Für die Zahl der Urkunden bedeutet das im konkreten Fall, dass ich etwa bei der Beauftragung von drei dele- 
mehr als doppelt so viel wie im Jahrzehnt von 1180 bis 1189, in dem sich 43 Stücke für sizilische und kalabrische Empfänger fassen lassen ${ }^{21}$. Hinzu kommen noch mindestens 16 bei Potthast verzeichnete Stïcke, die in den Registern nicht enthalten und nur anderweitig überliefert $\operatorname{sind}^{22}$. Doch auch diese 103 Stücke in einem Jahrzehnt dürften noch nicht alles bieten, was in den Archiven der sizilischen und kalabrischen Empfänger zu finden ist, denn das Material ist in seiner Gesamtheit nach 1198 trotz - oder vielleicht auch gerade wegen der besseren Quellenlage erheblich schlechter aufbereitet, als dies für den Bereich vor 1198 durch die Italia Pontificia der Fall ist ${ }^{23}$. Da die Ausführungen dieses Beitrags für die Zeit nach 1198 allein auf gedrucktem Material beruhen, können Sie für die letzten zehn Jahre des Untersuchungszeitraums lediglich eine Skizze sein, ohne den Anspruch zu erheben, das urkundliche Material vollständig erfasst zu haben, was in etlichen Aspekten für die Zeit vor 1198 dank der Aufarbeitung in der Italia Pontificia 10 annähernd möglich ist.

Aufgrund der schlechteren Erfassung des Materials nach 1198 ist der Charakter des verfügbaren Quellenkorpus noch zentrumslastiger, als er dies durch das Einsetzen der Registerüberlieferung ohnehin bereits ist ${ }^{24}$. Das Material scheint daher nicht nur zu explodieren, sondern ebenso seinen Charakter grundlegend zu verändern. Doch wie lässt sich das Material in seiner unterschiedlich aufgearbeiteten Form über die Epochengrenze von 1198 hinweg nutzen, ohne durch die Bedingungen der Überlieferung zu einem gänzlich verzerrten Bild zu kommen, bei dem Innozenz III. im Vergleich zu seinen Vorgängern als der alles beherrschende Papst erscheint? Bildet der Pontifikat Innozenz III. für Sizilien und Kalabrien tatsächlich eine neue Qualität, die sich in der Anzahl der ausgestellten Urkunden widerspiegelt, wie es eine graphische Darstellung der Urkundenzahl in Jahrzehnten suggeriert?

gierten Richtern davon ausgegangen bin, dass alle drei Richter ein entsprechendes Schreiben erhalten haben. Bisweilen wird die Mehrfachausfertigung in den Registerbänden auch vermerkt, so etwa das Schreiben Reg. Inn. III., II/236, das an 50 unterschiedliche Adressen geschickt wurde, folglich auch $50 \mathrm{mal}$ ausgestellt worden war, wie der Eintrag in das Register verdeutlicht, vgl. Reg. Inn. III, II/236 S. 453-456.

$21 \mathrm{Zu}$ den Zahlen siehe unten Anm. 26.

22 Potthast 93, 147, 209, 560, 593, 1138, 1462, 1481, 1482, 1483, 1484, 1485, 1592, 1593,2292 u. 2315.

23 So liegt den Angaben bei Potthast keine systematische Erfassung der Empfängerüberlieferung zugrunde, sondern allein die Zusammenstellung des gedruckten Materials. Im Rahmen der Italia Pontificia dürfte gemessen am erfassten Material nur noch mit geringfügigen Nachträgen zu rechnen sein. Vgl. zum Abschluss der Italia Pontificia jüngst auch den Aufruf von Klaus HerBers: 100 Jahre Italia Pontificia (1906-2006) - Anregungen zur Abrundung, in: QFIAB 87 (2007) S. 374-379.

24 Die Edition der Register weist nur bei acht Stücken auch eine Empfängerüberlieferung nach, bei Reg. Inn. III., I/106, I/316, I/410, I/411, II/139, IX/157, IX/158 u. $\mathrm{XI} / 4$. 


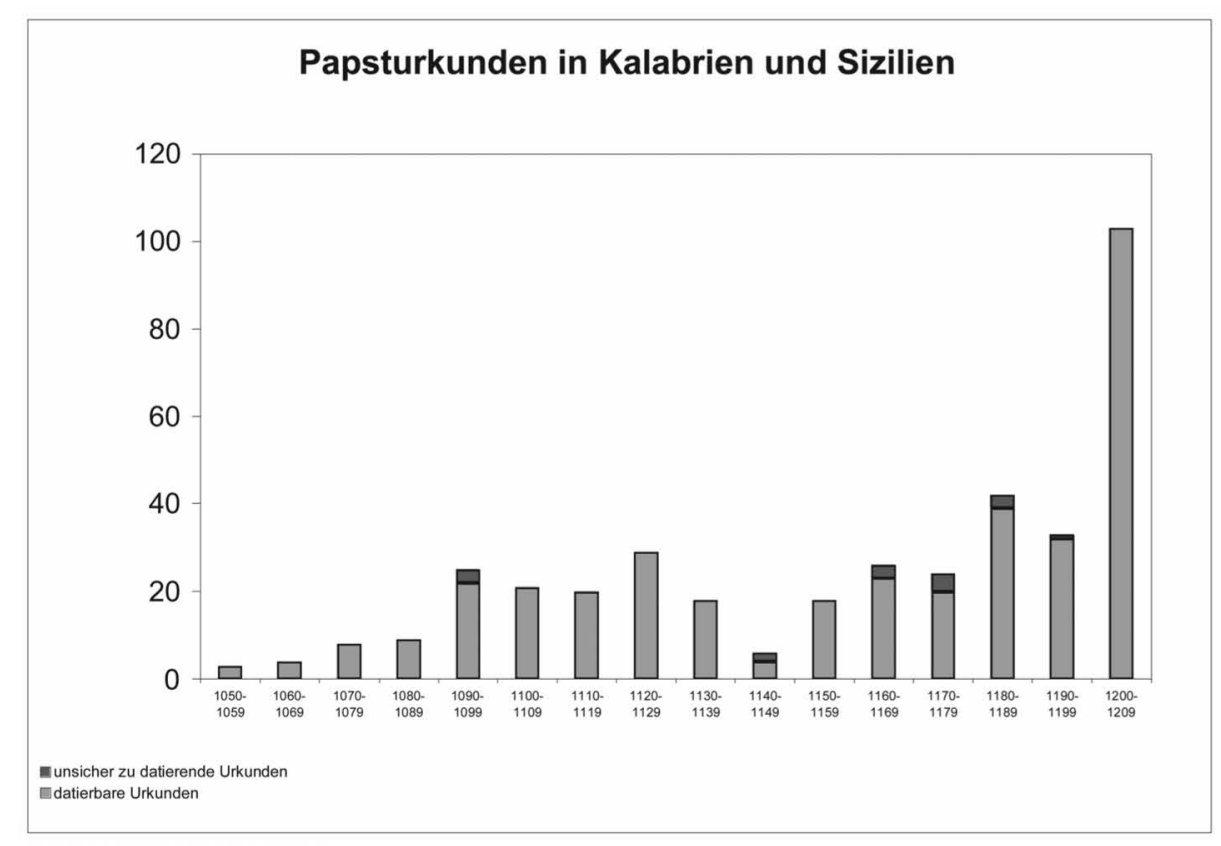

Nach bescheidenen Anfängen in der Mitte des 11. Jahrhunderts kommt es zu einer allmählichen Steigerung, die kurz vor der Jahrhundertwende ihren Höhepunkt erreicht. Die 1130er Jahre bringen jedoch eine erhebliche Reduzierung und in den 40er Jahren des 12. Jahrhunderts sind nur vier Urkunden zu fassen $^{25}$, ebenso viele wie im Jahrzehnt von 1060 bis 1069. Nach einer erneuten Steigerung der ausgestellten Urkunden kommt es mit der Epochengrenze von 1198 schließlich zu einem eklatanten Sprung, so dass sich die Zahl der überlieferten Papsturkunden nun verdreifacht ${ }^{26}$. Ist die unteritalienische Kirche, die sich zuvor dem Zugriff der Päpste nicht zuletzt durch die dominante Stellung der sizilischen Könige entzog, nun fest an Rom angebunden? Wand-

25 Bereits Norbert KAMP: Der unteritalienische Episkopat im Spannungsfeld zwischen monarchischer Kontrolle und römischer , libertas" von der Reichsgründung Rogers II. bis zum Konkordat von Benevent, in: Società, Potere e popolo nell'età di Ruggero II, Bari 1979 (Centro di studi normanno-svevi, Università degli Studi di Bari, Atti 3), S. 99-132, hier S. 117f., wies darauf hin, dass es Roger II. ab 1140 offenbar gelungen war, die Kontakte zwischen den unteritalienischen Bischöfen und der Kurie zu unterbinden.

26 Die Zahlen sind im einzelnen für die dargestellten Jahrzehnte: 3 (1050-1059); 4 (1060-1069): 8 (1070-1079); 9 (1080-1089); 22 u. 3 undatierte (1090-1099); 21 (1100-1109); 20 (1110-1119); 29 (1120-1129); 18 (1130-1139); 4 u. 2 undatierte (1140-1149); 18 (1150-1159); 23 u. 3 undatierte (1160-1169); 20 u. 4 undatierte (1170-1179); 39 u. 3 undatierte (1180-1189); 32 und eine undatierte (1190-1198) und 103 (1198-1209). 
ten sich die unteritalienischen Prälaten ab 1198 wesentlich häufiger aus eigenem Antrieb an Rom?

Ein genauer Blick auf die Urkundenarten bewahrt davor, die aufgeworfene Frage vorschnell zu bejahen. Denn die Register überliefern erstaunlich stark das Wollen des Papstes - immerhin sind 24 der 87 Stücke Mandate. Hinzu kommen noch zwölf Informationsschreiben des Papstes, in denen Innozenz III. von sich aus Geistliche oder Weltliche über sein Handeln informiert. Ein nicht unbeträchtlicher Teil dieser Stücke ist durch die Vormundschaftsregierung des Papstes für den minderjährigen Friedrich II. bedingt, welche die Energien des Papstes band, so dass er in einem Brief von 1206 an den immer noch minderjährigen Friedrich II. seiner Hoffnung Ausdruck gab, dass die für Innozenz III. mühselige und kostspielige Vormundschaftsregierung bald ein Ende habe ${ }^{27}$. Auch über den Tod Markwards von Annweiler hinaus tritt Innozenz III. in seinen Briefen als tadelnder, mahnender oder befehlender Papst in Aktion, der sich intensiv um die Verhältnisse in Unteritalien bemühte. Gleichwohl ist auch deutlich zu erkennen, dass ein erheblicher Teil der Mandate nicht kirchliche Belange betrifft. Vielmehr steht die Absicherung der Königsherrschaft Friedrichs II. in einem Großteil der Schreiben Innozenz' III. im Vordergrund. Das Königreich Sizilien wird damit zwar ein „Interessensraum“ der Kurie, doch vor allem in Hinblick auf die politische Entwicklung ${ }^{28}$. Die Dimension des so beschriebenen Einblicks in das päpstliche Wollen, der mit der Überlieferung der päpstlichen Register möglich ist, wird zumal durch die Gegenüberstellung der Überlieferung vor und nach 1198 deutlich. Sind für das erste Jahrzehnt Innozenz' III. - in dem sogar zwei Registerbände fehlen - 24 Mandate überliefert, so sind es für den gesamten Untersuchungszeitrum bis 1198 lediglich 14 Stücke, die durch die Empfängerüberlieferung auf uns gekommen sind.

Der von Innozenz ausgesprochene Tadel, sein Mahnen und Befehlen lässt erkennen, wie schnell man in Rom auf bestimmte Entwicklungen reagierte, was voraussetzt, dass man rasch informiert wurde. Doch wie reagierte man auf diesen Tadel, dieses Mahnen und Befehlen vor Ort, und veränderten die unteritalienischen Kirchen aufgrund dieser permanenten Handlungsanweisungen ihr Verhältnis zu Rom? Waren die Schreiben des Papstes gleichsam eine einseitige Kommunikation, bei der eine Verlautbarung nach der anderen die päpstliche Kanzlei verließ, ohne dass dies Folgen gezeitigt hätte, oder war der Effekt doch eine verstärkte Rückkopplung der unteritalienischen Kirchen an

27 So in Reg. Inn. III., IX/157 S. 283 Z. 11-14.

28 Der Begriff des Interessensraumes wird hier im Sinne von Götz-Rüdiger TEWES: Die päpstliche Kurie und die europäischen Länder am Vorabend der Reformation, Tübingen 2001 (Bibliothek des Deutschen Historischen Instituts in Rom 95), S. 135f., benutzt; vgl. auch DERS.: Zwischen Universalismus und Partikularismus: Zum Raumbewußtsein an der Kurie des Spätmittelalters, in: Raumerfassung und Raumbewußtsein im späteren Mittelalter, hg. v. Peter MORAw, Stuttgart 2002 (VuF 49), S. 31-85, hier S. 33f.; sowie allgemein auch Hans-Joachim SCHMIDT: Raumkonzepte und geographische Ordnung kirchlicher Institutionen im 13. Jahrhundert, in: ebd., S. 87-125. 
Rom? Wandten sich die Kirchen Kalabriens, angetrieben vom Stacatto der Mahnungen, nun auch von sich aus häufiger an die Kurie und ließen sich ihre Position von Rom bestätigen? Mit Blick auf die Überlieferung in den päpstlichen Registern heißt das konkret: Wie viele Rechtsbelehrungen, Urkunden-, Rechts- und Papstschutzbestätigungen oder -verleihungen enthält das Material und ebenso, wie häufig wandte man sich nun an die Kurie, um die Entsendung bzw. Beauftragung eines Legaten oder delegierten Richters zu erreichen? Dabei wird die hohe Zahl von 103 Urkunden doch stark relativiert.

Denn es fällt sofort auf: Nach 1198 sind kaum Privilegien zu fassen. In den Registerbänden 1 bis 11 sind lediglich fünf Stücke zu fassen, die als klassische Privilegien anzusprechen sind, die dem Empfänger Rechte oder Besitzungen bestätigen oder gewähren ${ }^{29}$. Bedingt sind dem noch drei weitere Urkunden hinzuzuzählen, in denen Innozenz III. die Aufhebung von Besitzentfremdungen genehmigte ${ }^{30}$. Mit anderen Worten: Urkunden, die eine Intervention der sizilischen und kalabrischen Empfänger voraussetzten und die im Archiv der Empfänger eine gute Überlieferungschance haben, finden sich in den Registern Innozenz' III. kaum ${ }^{31}$. $\mathrm{Zu}$ diesen fünf Privilegien aus den Registern kommen noch drei hinzu, die jedoch nicht in den Registern überliefert sind ${ }^{32}$. Die Zahl von acht Privilegien spricht jedoch kaum für eine durch die Vormundschaftsregierung Innozenz' III. intensivierte Bindung der Kirchen Siziliens und Kalabriens an Rom. Die Zahl der Privilegien vor und nach der Epochengrenze von 1198 ist hingegen erstaunlich konstant ${ }^{33}$. In dieser Perspektive erweist sich das Epochenjahr 1198 als weniger einschneidend als gedacht ${ }^{34}$.

Nach diesen Vorbemerkungen zu den Überlieferungsbedingungen und deren Folgen für die Aussagekraft des Materials nun zu den beiden Regionen Sizilien und Kalabrien, die im Folgenden getrennt behandelt werden. Zunächst

29 Reg. Inn. III., I/316, V/29, VI/138, VII/148 u. 149.

30 Reg. Inn. III., I/180, I/250 u. I/294.

31 Erstaunlich ist jedoch, dass nach Ausweis der Registeredition allein das Privileg Reg. Inn. III., I/316 an Ebf. Carus von Monreale auch auf der Empfängerseite überliefert ist.

32 Potthast 93 (an Ebf. Carus von Monreale), 147 (an Ebf. Berard von Messina) u. 209 (an Ebf. Caro von Monreale).

33 Der Befund ist jedoch nicht ohne weiters auf andere Regionen übertragbar. So enthalten die Register Innozenz' III. etwa für die Regionen Ungarn und Polen erheblich mehr Privilegien, als für den Zeitraum vor $1198 \mathrm{zu}$ fassen sind, siehe dazu auch den Beitrag von Przemyslaw Nowak in diesem Band.

34 Vgl. auch die Beobachtungen von Klaus HeRBERs: Päpstliche Autorität und päpstliche Entscheidungen an der Wende vom 9. zum 10. Jahrhundert, in: Recht und Gericht in Kirche und Welt um 900, hg. v. Wilfried HARTMANN unter Mitarbeit von Annette GRABOWSKY, München 2007 (Schriften des Historischen Kollegs. Kolloquien 69), S. 7-30, hier S. 9-14 u. 29, der für das 9. Jahrhundert die Konstanz der Nachfrage nach Privilegien hervorhebt, unabhängig von der tagespolitischen Situation in Rom. 
zu Sizilien: Für Sizilien sind zwischen 1046 und 1209 insgesamt 188 Urkunden zu verzeichnen. Die chronologische Verteilung stellt sich wie folgt dar: $:^{35}$

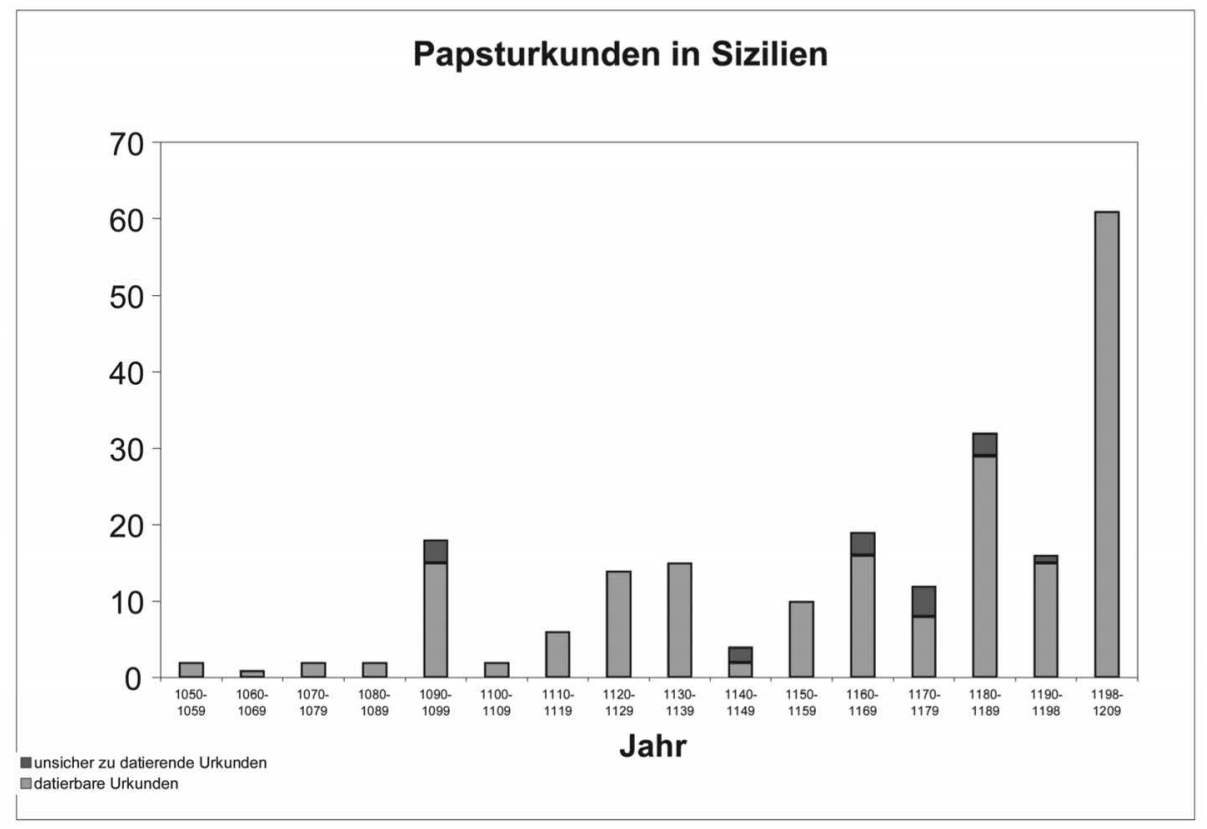

Die Verteilung weicht damit zumindest vor dem letzten Jahrzehnt des Untersuchungszeitraums deutlich von der Urkundenverteilung für den kalabrischen Raum ab, für den mit 218 Urkunden in etwa genauso viele Urkunden vorliegen. Zwar bildet der Pontifikat Calixts II. (1119-1124) auf den ersten Blick keinen vergleichbar tiefen Einschnitt in der Kommunikation zwischen Papst und sizilischer Kirche; doch der Charakter der nach 1123 für sizilische Empfänger ausgestellten Stücke hatte sich im Vergleich zum davorliegenden Zeitraum verändert. Dieser Wandel dokumentiert die Distanz zwischen Papsttum und sizilischen Einzelkirchen, die durch das Zerwürfnis zwischen Roger II. und Calixt II. entstanden war. Denn alle Stücke, die von diesem Zeitpunkt an bis zu den ersten Urkunden Anaklets II. ausgestellt wurden, sind fast aus-

352 (1050-1059), 1 (1060-1069), 2 (1070-1079), 2 (1080-1089), 15 u. 3 undatierte (1090-1099), 2 (1100-1109), 6 (1110-1119), 14 (1120-1129), 15 (1130-1139), 2 u. 2 undatierte (1140-1149), 10 (1150-1159), 16 u. 3 undatierte (1160-1169), 8 u. 4 undatierte (1170-1179), 29 u. 3 undatierte (1180-1189), 15 u. eine undatierte (1190-1198) und 61 (1198-1209). Die Summe der einzeln ausgewiesenen Urkunden des Jahrzehnts von 1198 bis 1209 für Kalabrien und Sizilien übersteigt die Zahl von 103 Urkunden um 20. Dies ist dadurch zu erklären, dass die das gesamte Königreich betreffenden Urkunden in beiden Räumen gezählt wurden, in der Gesamtstatistik jedoch nur einmal erscheinen. 
schließlich politischer Natur und wurden zwischen Papst und Roger ausgetauscht. Mit anderen Worten: Auch zwischen den sizilischen Kirchen und den Päpsten kam es nach dem Bruch zwischen Roger II. und Calixt II. zu einer Art Funkstille, die auf den dominierenden Einfluss des Hauteville zurückzuführen sein dürfte ${ }^{36}$.

Der briefliche oder urkundliche Austausch zwischen dem Papst und den Einzelkirchen endet nach Ausweis der Überlieferung auf Sizilien ebenso abrupt wie in Kalabrien nach 1122/23. Doch vor allem die Stücke Anaklets II. unterscheiden die sizilische Kirche von der kalabrischen, bei der es sofort nach 1122 bis in die 1160er Jahre gleichsam zu einer Kommunikationsunterbrechung zwischen Ortskirchen und Papsttum kam ${ }^{37}$.

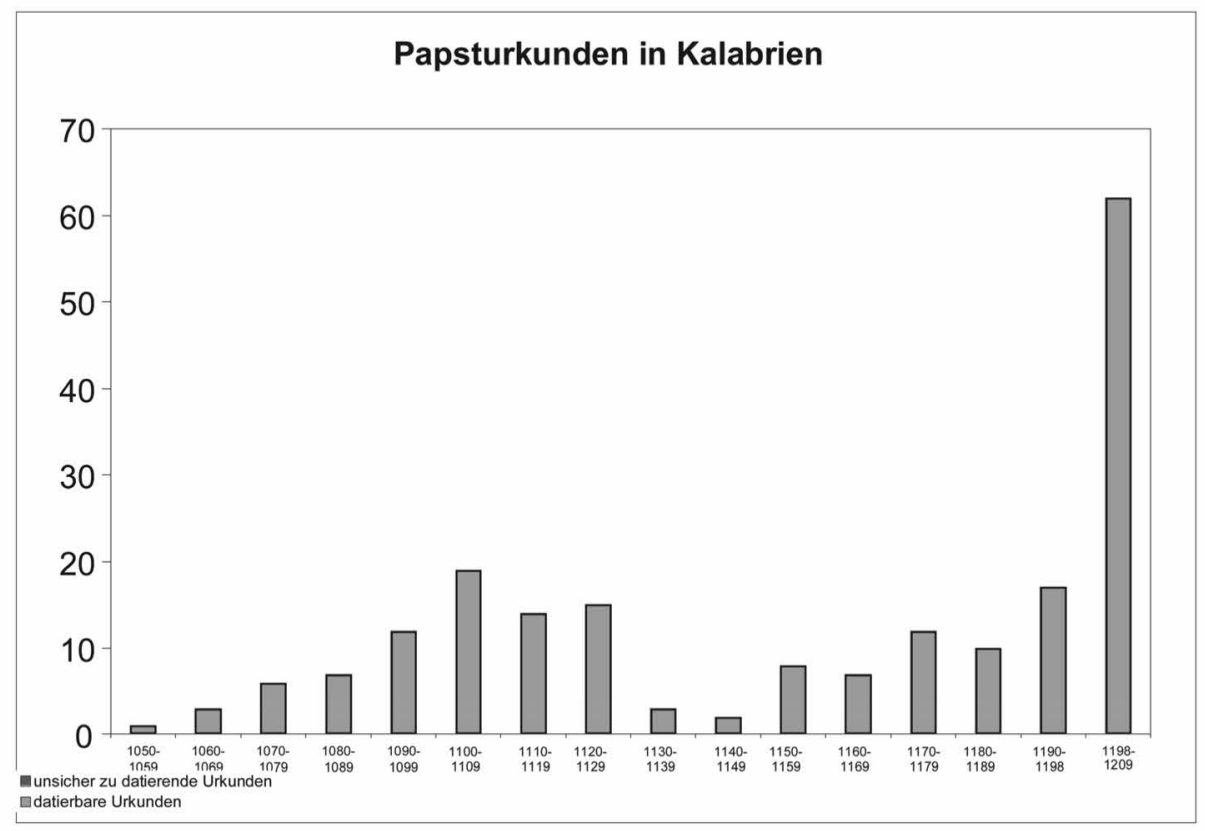

Dass in der Zeit bis 1090 für Sizilien kaum Urkunden zu verzeichnen sind, ist durch die schlichte Tatsache zu erklären, dass die Insel bis zu diesem Zeitpunkt in muslimischer Hand war und sich die noch vorhandenen Kirchen offenbar

$36 \mathrm{Vgl}$. zu den Ursachen und direkten Folgen des Zerwürfnisses zusammenfassend JOHRENDT: Sonderfall (wie Anm. 2) S. 257f.

37 In Zahlen ausgedrückt gestaltet sich die Verteilung der Urkunden wie folgt: 1 (10501059), 3 (1060-1069), 6 (1070-1079), 7 (1080-1089), 12 (1090-1099), 19 (11001109), 14 (1110-1119), 15 (1120-1129), 3 (1130-1139), 2 (1140-1149), 8 (11501159), 7 (1160-1169), 12 (1170-1179), 10 (1180-1189), 17 (1190-1198) u. 62 (11981209). Siehe auch die Bemerkungen bei JoHrendT: Sonderfall (wie Anm. 2) S. 241 Anm. 22. 
weniger an Rom orientierten. Das Hochschnellen der Urkunden für sizilische Empfänger nach 1090 ist durch den mit der Eroberung der Insel verbunden Regelungsbedarf zu erklären, da hier erst in Abstimmung mit den Päpsten eine neue Metropolitanstruktur geschaffen werden musste ${ }^{38}$. Zwar kommt es danach auf Sizilien ebenso wie in Kalabrien nicht zu einer dauerhaften und kontinuierlichen Zunahme von Urkunden, doch liegt der harte Einschnitt nicht bereits nach 1122 und dem Zerwürfnis zwischen Roger II. und Calixt II. Vielmehr sind in den 30er Jahren mit 15 Urkunden ebenso viele Stücke wie in den 1120er Jahren (14 Urkunden) nachzuweisen, davon zwölf von Anaklet II. ausgestellt, so dass der Einbruch der Urkundendichte in Italien erst nach dem Tod Anaklets II. erfolgte. Erneut war es die Bistumsorganisation, die hier dafür sorgte, dass Urkunden von Anaklet II. ausgestellt wurden - was in Kalabrien mit einer inzwischen eher gefestigten Kirchenverfassung nicht mehr notwendig war ${ }^{39}$. Für beide Regionen ist dann in den 1150er Jahren ein erneutes Einsetzen der Urkundenausstellung zu beobachten, was wohl als eine Widerannäherung der Ortskirchen an Rom zu interpretieren ist.

\section{Papstreisen und Legationen}

Kamen die Päpste in der Person Urbans II., Paschalis' II. und Calixts II. bis 1122 immer wieder nach Kalabrien ${ }^{40}$, so betrat während des Untersuchungszeitraums kein einziger von ihnen jemals die Insel. Mit anderen Worten: die oberste Spitze der Kirche war in Kalabrien auch persönlich anwesend, auf Sizilien hingegen nie. Päpstliche Reisen, ein wesentliches Instrument für die In-

38 Vgl. dazu Horst EnZENSBERGER: Die lateinische Kirche und die Bistumsgründungen in Sizilien zu Beginn der Normannenherrschaft http://www.medioevoitaliano.org/ rassegna.2.htm (25.08.2010) (Rassegna Storica online 2, 2000); sowie jetzt auch BECKER: Graf (wie Anm. 1) S. 168-189, die S. 189 den entscheidenden Einfluss Rogers I. betont, dem die Päpste sich auch hinsichtlich der Bistumsorganisation durch die von ihm geschaffenen Fakten beugen mussten; dort auch die weitere Literatur zu den einzelnen Bistümern.

39 Die Anerkennung der von Anaklet II. befürworteten Bistumsgründungen von Lipari und Cefalù erfolgte jedoch nicht unmittelbar, sondern zog sich in den beiden genannten Fällen sogar bis zu Alexander III. hin, vgl. dazu Graham A. LOUD: The Papacy and the Rulers of Southern Italy, 1058-1198, in: The Society of Norman Italy, ed. by Graham A. Loud/Alex METCALFe, Leiden u. a. 2002, S. 151-184, hier S. 169-175; KAMP: Episkopat (wie Anm. 25) S. 110f.

40 Vgl. JOHRENDT: Sonderfall (wie Anm. 2) S. 245-247; die Bedeutung der Reisen für die Hinführung der unteritalienischen Kirche auf Rom betont LOUD: Latin Church (wie Anm. 5) S. 208. Zu den päpstlichen Reisen nach Frankreich vgl. jetzt Rolf GROSSE: „Ubi papa, ibi Roma“ - Papstreisen nach Frankreich im 11. und 12. Jahrhundert, in: Päpstliche Herrschaft im Mittelalter. Funktionsweisen - Strategien - Darstellungsformen, hg. von Stefan WeINFURTER, Ostfildern 2012 (Mittelalter-Forschungen 38), S. 313-334. 
tegration der Ortskirchen in die Römische Kirche und deren Ausrichtung am römischen Zentrum, fanden auf Sizilien nie und in Kalabrien nach 1122 nicht mehr statt ${ }^{41}$. Weihen von Bischöfen und Äbten durch den Papst konnten wesentlich einfacher durchgeführt werden, wenn der Papst vor Ort war - auf diese Weise konnte er mehr Bischöfe und Äbte erfassen. Auch Urkunden waren einfacher zu erwirken, wenn die päpstliche Kanzlei nicht hunderte von Kilometern entfernt war, sondern nur eine Tagesreise oder gar vor $\mathrm{Ort}^{42}$. Dasselbe galt für kirchenrechtliche Fragen hinsichtlich der Situation in der eigenen Kirche - war der Papst vor Ort, so wurden diese Fragen leichter an ihn herangetragen und eröffneten Rom damit die Möglichkeit zu einer normativen Äußerung, die über die aktuelle Situation hinaus mit Bezug auf den Papst Wirkung entfalten konnte.

Zwar stellt die Entwicklung der kalabrischen Kirche nach 1122 die Integrationskraft der Reisen in Frage, denn nach dem Zerwürfnis zwischen Roger II. und Calixt II. brachen die Kontakte zwischen der kalabrischen Kirche und Rom fast vollständig ab. Andererseits ist kaum vorstellbar, dass die physische Präsenz des vicarius Petri für die Integration der Ortskirchen nach dem eben beschriebenen Muster keine Wirkung gehabt hätte, und die enge Bindung der kalabrischen Kirche bis 1122 an die Kurie dürfte zu Teilen auch durch die physische Präsenz des Papstes in dieser Region bedingt gewesen sein. Gleichwohl war die Wirkung der Reisen in Kalabrien nicht von einem dauerhaften Erfolg gekrönt ${ }^{43}$.

Doch wie war es um die Wirkung der Legationen bestellt? Sizilien wurde von den Päpsten nicht bereist und auch den päpstlichen Legaten blieb die Insel verschlossen. Denn das 1098 von Urban II. an Roger I. ausgestellte Legationsmandat, das den Zutritt von päpstlichen Legaten auf der Insel ebenso wie Appellationen an die Kurie untersagte, blieb faktisch bis zum Tod Heinrichs VI. in $\mathrm{Kraft}^{44}$.

41 Nach Apulien zog hingegen Anaklet II., der vermutlich am 28. November 1130 in Bari weilte, vgl. LOUD: Latin Church (wie Anm. 5) S. 224.

42 Zum Zusammenhang von päpstlichen Reisen und der Ausfertigung von Papsturkunden vgl. jüngst am Beispiel Leos IX. Joachim DAHLHAUS: Urkunden, Itinerar und Festkalender. Bemerkungen zum Pontifikat Leos IX., in: Aspects diplomatiques des voyages pontificaux, hg. v. Bernard BARBICHE/Rolf Grosse, Paris 2009 (Studien und Dokumente zur Gallia Pontificia 6), S. 7-29. Für das 13. Jahrhundert vgl. Tommaso di Carpegna FALCONIERI/Fabio BOVALINO: „Commmovetur sequenti die curia tota“. L'impatto dell'itineranza papale sull'organizzazione ecclesiastica e sulla vita religiosa, in: Itineranza pontificia. La mobilità della Curia papale nel Lazio (secoli XII-XIII), a cura di Sandro CAROCCI, Roma 2003 (Nuovi studi storici 61), S. 101-175.

43 Vgl. Johrendt: Sonderfall (wie Anm. 2) S. 247. So betonte auch KamP: Episkopat (wie Anm. 25) S. 102f., dass die päpstlichen Reisen von keinem dauerhaften Erfolg gekrönt waren.

44 Vgl. Johrendt: Sonderfall (wie Anm. 2) S. 237f,; jüngst auch BeCKER: Graf (wie Anm. 1) S. 141-151. 
Doch auch die Legationen nach Kalabrien lassen sich - sofern sie in den Quellen Niederschlag gefunden haben - an einer Hand abzählen ${ }^{45}$. Unter Nikolaus II. und Alexander II. tritt Erzbischof Arnulf von Cosenza als vicarius sanctae Romane ecclesiae auf, ohne dass dessen genauer regionaler Zuständigkeitsbereich zu fassen wäre, unter Urban II. schließlich der Bischof von Cassano. Daneben ist unter Paschalis II. noch Lanuinus, ein Schüler Brunos des Karthäusers, als päpstlicher Legat anzusprechen, jedoch nicht als Vikar. Die weiteren überlieferten Legationen bis 1198 und darüber hinaus wurden ausschließlich von Kardinälen durchgeführt: Unter Calixt II. 1119 von Kardinalpriester Desiderius von S. Prassede, und 1121 drang eventuell auch Kardinalpriester Hugo von SS. Apostoli nach Kalabrien vor. Danach folgt erst wieder 1165 eine Legation des Kardinalbischofs Bernhard von Porto und S. Rufina, der seit dem Ausbruch des alexandrinischen Schismas fest auf der Seite Alexanders III. stand, gemeinsam mit Kardinaldiakon Manfred von S. Gregorio in Velabro. Der für das Regno als Legat ernannte Petrus Capuanus ist hingegen nicht in Kalabrien nachzuweisen ${ }^{46}$. Von den seit Alexander III. häufiger zu fassenden Legationen in das Königreich scheint Kalabrien offenbar unberührt geblieben zu sein ${ }^{47}$.

Noch eindeutiger stellt sich die Situation bis 1198 für die Insel Sizilien dar. Die durch das Privileg Urbans II. gewährten Rechte einer ständigen Legation des Herrschers nahmen die sizilischen Großgrafen und späteren Könige offenbar intensiv wahr, so dass es nicht verwundert, dass sich auf der Insel Sizilien bis 1198 keine kirchlichen Handlungen eines päpstlichen Legaten nachweisen lassen $^{48}$. Allein die wohl 1097/98 erfolgte und bei Malaterra überlieferte Ernennung des Bischofs Robert von Troina, der Keimzelle des Bistums und später Erzbistums von Messina, zum Legaten für Sizilien wäre hier anzuführen $^{49}$. Doch diese Übertragung fand offenbar - obwohl Robert als Vertrauter

45 Bereits Loud: Control (wie Anm. 12) S. 153, bemerkte, dass die Päpste das ihnen für das Festland zustehende Legationsrecht dort im Vergleich zu anderen Regionen nur sehr sparsam einsetzten.

$46 \mathrm{Zu}$ den Legationen in Kalabrien bis 1198 vgl. JOHREnDT: Sonderfall (wie Anm. 2) S. 247-251, dort die einzelnen Nachweise.

47 Von einer neuen Intensität unter Alexander III. für das gesamte Königreich spricht Marcel PACAUT: Papauté, Royauté et épiscopat dans le Royaume de Sicile, in: Potere, società e popolo nell'età dei due Guglielmi. Atti delle quarte giornate normanno-sveve Bari-Gioia del Colle, 8-10 ottobre 1979, Bari 1981 (Centro di studi normanno-svevi, Università degli Studi di Bari, Atti 4), S. 31-61, hier S. 59 f.

48 BECKER: Graf (wie Anm. 1) S. 146-149 betont, dass die Verleihung der apostolischen Legation ,für Roger I. in seiner kirchenpolitischen Praxis eher von marginaler Bedeutung war" (S. 147).

49 IP 10 S. 338 Nr. *19 nennt als Zeitpunkt (1097?), während BECKER: Graf (wie Anm. 1) S. 141f. von Frühjahr 1098 ausgeht. Sicherlich verfehlt ist jedoch die Interpretation von ebd., S. 142, dass Robert als legatus natus eingesetzt worden sei. Zunächst ist die Anwendung der Begriffe legatus natus und legatus a latere für die Zeit vor dem ausgehenden 12. Jahrhundert anachronistisch, vgl. bereits Paul HinschiUs: System des ka- 
des sizilischen Großgrafen gelten kann ${ }^{50}$ - nicht das Wohlwollen Rogers I., der auf seine Art darauf reagierte. Er sah hier wohl vor allem einen Widerspruch zu den Legationskompetenzen, die Urban II. Roger I. im Juli 1098 übertragen hatte, und deren Inhalt ihm offenbar bereits zuvor klar war ${ }^{51}$. Den Widerspruch löste Roger I. auf normannisch-pragmatische Weise, indem er Robert schlicht gefangen nehmen ließ.

Aus der Sicht des sizilischen Großgrafen mochte sich durch die Übertragung der Legatengewalt an ihn für seine Kirchenpolitik nichts geändert haben $^{52}$, doch aus päpstlicher Perspektive war diese Übertragung sicherlich kein Glanzlicht der römischen Zentralisierungsbemühungen und so wundert es nicht, dass die nachfolgenden Päpste sich mehrfach um eine Aufhebung des Privilegs bemüht hatten. Die kirchenpolitischen Konsequenzen des Legationsprivilegs für Roger I. traten im Vergleich zu anderen Regionen deutlich zutage, denn das kirchliche Instrument der Legationen kam auf Sizilien nicht zur Anwendung. Alle Nachrichten über Legaten, die nach Sizilien gingen oder von dort zur Kurie zurückkehrten, betreffen so gut wie ausschließlich politische Angelegenheiten. Ein bezeichnendes Beispiel ist die Reise des Kardinalpresbyters Johannes von S. Anastasia 1169 nach Palermo. Er überbrachte dem Elekten Walter von Palermo das Pallium, doch die Weihe wurde nicht durch den Kardinallegaten, sondern durch die Suffragane Palermos durchgeführt ${ }^{53}$. Diese geringe Zahl an Legationen sowohl in Kalabrien als auch auf Sizilien ist vielleicht auch zu einem Teil dadurch zu erklären, dass die sizilischen Könige

tholischen Kirchenrechts mit besonderer Rücksicht auf Deutschland, Bd. 1, Berlin 1869, S. 512f.; doch es geht auch in der Sache fehl. Denn eine dauerhafte Kopplung der Legation auf Sizilien an das Bistum Troina bzw. das Erzbistum Messina ist der Passage bei Malaterra nicht zu entnehmen. Dort heißt es allein: apostolicus jamdudum Robertum, episcopum Traynensem, comite inconsulto, legatum in Sicilia ad exequendum jus sanctae Romanae Ecclesiae posuerat, Gaufredus Malaterra, De rebus gestis Rogerii Calabriae et Siciliae comitis et Roberti Guiscardi ducis fratris eius, ed. Ernesto PONTIERI, Bologna 1925-1928 (Rerum Italicarum Scriptores 5,1), lib. IV c. 29 S. 107 Z. $6 f$.

$50 \mathrm{Zu}$ den engen Bindungen zwischen Roger I. und Robert von Troina vgl. BECKER: Graf (wie Anm. 1) S. 142. Dort findet sich auch der Hinweis, dass Robert von Gregor VII. zum Bischof geweiht worden sei, jedoch ohne Quellenangabe. Für eine vollzogene Weihe gibt es keinen Nachweis. Es ist lediglich die Antwort Gregors VII. auf eine Anfrage überliefert, dass er den Elekten Robert weihen werde, wenn dieser nach Rom käme, vgl. IP 10 S. 337 Nr. 17, Edition bei Das Register Gregors VII., ed. Erich CASPAR, Berlin 1920/1923 (MGH Epp. sel. 2), IX/25, S. $607 f$.

$51 \mathrm{Zu}$ den einzelnen Schritten der Übertragung vgl. zusammenfassend BECKER: Graf (wie Anm. 1) S. 143-145.

52 So völlig zutreffend BECKER: Graf (wie Anm. 1) S. 147, die der „stellvertretenden Legatenfunktion“ Rogers I. eine „,eher ... marginale Bedeutung“ für dessen kirchenpolitische Praxis zuweist, zumal der vom Papst verliehene Titel in den Urkunden des Herrschers lediglich eine geringen Niederschlag gefunden habe. Vgl. auch LOUD: Control (wie Anm. 12) S. $147 f$.

53 IP 10 S. 232 Nr. 32, vgl. die Parallelschreiben. Zur Person Walters vgl. Kamp: Kirche (wie Anm. 10) Bd. 3 S. 1112-1119. 
vor allem in der zweiten Hälfte des 12. Jahrhunderts den Päpsten wenig Anlass boten, intervenieren zu müssen, da sie sich - in dem ihnen sinnvoll erscheinenden Rahmen - um eine Einhaltung der kirchlichen Normen bemühten und so offenbar auch wenig Missstände vorlagen ${ }^{54}$.

Das Bild scheint sich mit dem Regierungsantritt Innozenz' III. zu ändern, wobei auch hier in der Mehrzahl der Fälle nicht die Anbindung der unteritalienischen Kirchen an Rom, sondern bedingt durch die Vormundschaft des Papstes für Friedrich II. politische Aktionen aufgrund der aktuellen Lage im Regno im Vordergrund standen ${ }^{55}$. Es ist davon auszugehen, dass die Legaten jedoch nicht allein politisch tätig waren, sondern stets kirchenpolitische, politische sowie militärische Aktionen miteinander verbanden. Doch ist aufgrund der schlechten Quellenaufarbeitung nicht immer klar, ob die Legaten auch den Weg bis nach Kalabrien oder gar bis Sizilien fanden, und wenn ja, ob sie dann durch Kalabrien gezogen waren ${ }^{56}$.

Dennoch ist die Intensität der Legationen nach 1198 zumal im Kontrast zur davor liegenden Zeit beeindruckend. Zwar ist eine Legation des Kardinalbischofs Octavianus von Ostia und Velletri im Herbst 1198, auf welcher der Legat den Treueid der Kaiserin entgegennehmen sollte, fraglich ${ }^{57}$. Ebenso ist unklar, wo genau sich der bereits Ende 1198 zusammen mit Kardinaldiakon Gerardus von S. Adriano in der Terra di Lavoro tätige Kardinalpresbyter Johannes de Salerno von S. Stefano in Celiomonte bei seiner erneuten Legation vom November 1199 in das Königreich Sizilien aufhielt ${ }^{58}$. Doch noch 1199 sind zwei Kardinallegaten sicher auf Sizilien nachzuweisen: Auf der Insel Sizilien ist in der ersten Hälfte des Jahres 1199 der Kardinaldiakon Gregorius de Sancto Apostolo von S. Maria in porticu tätig. Er nimmt die Lehnseide entgegen, verlässt jedoch rasch wieder die Insel, wohl auch auf Druck der königli-

54 Loud: Control (wie Anm. 12) S. 154.

55 So bereits resümierend Heinrich ZIMMERMANN: Die päpstliche Legation in der ersten Hälfte des 13. Jahrhunderts. Vom Regierungsantritt Innocenz' III. bis zum Tode Gregors IX. (1198-1241), Paderborn 1913 (Görres-Gesellschaft zur Pflege der Wissenschaft im katholischen Deutschland. Veröffentlichungen der Sektion für Rechts- und Sozialwissenschaft 17), S. 175-180.

56 Eine kurze Zusammenstellung der Legationen unter Innozenz III. bietet ZIMMERMANN: Legation (wie Anm. 55), wobei seine Ausführungen, die einen päpstlichen Auftrag bisweilen allzu schnell mit einer Durchführung der Legation gleichsetzen, stets zu überprüfen sind.

57 ZimMERMANN: Legation (wie Anm. 55) S. 25 Nr. 8 ging noch von einer Legation aus, doch hat Werner MALECZEK: Papst und Kardinalskolleg von 1191 bis 1216. Die Kardinäle unter Coelestin III. und Innocenz III., Wien 1984 (Publikationen des Historischen Instituts beim Österreichischen Kulturinstitut in Rom Abt. 1, 6), S. 82, darauf hingewiesen, dass im Grunde nicht klar ist, ob Octavianus seine Reise nicht abbrach, als er vom überraschenden Tod der Kaiserin erfuhr, der seine Reise gegenstandslos machte.

58 Vgl. MaleczeK: Papst (wie Anm. 57) S. 108; der Hinweis auf die erneute Legation fehlt bei ZIMMERMANN: Legation (wie Anm. 55) S. $26 f$. 
chen Familiaren hin ${ }^{59}$. In Messina stimmte er der Wahl des neuen Erzbischofs $I$. von Reggio Calabria zu, der in der Forschung traditionell mit Jakobus identifiziert wird ${ }^{60}$. Dessen Nachfolger als Legat, Kardinalpriester Cinthius von S. Lorenzo in Lucina konnte sich auf Sizilien offenbar besser durchsetzen. Seine im Herbst 1199 beginnende Tätigkeit wurde mit dem Sieg der päpstlichen Truppen über Markward von Annweiler bei Monreale gekrönt ${ }^{61}$. Bei seiner Reise nach Sizilien zog Cinthius offenbar auch durch Kalabrien und schiffte sich nicht direkt nach Sizilien ein ${ }^{62}$. Gemessen am politischen Erfolg der Legation sind nur wenige kirchliche Handlungen dieses Legaten bekannt, namentlich eine Urkunde für Joachim von Fiore und die Translation des Bischofs Walter von Palearia nach Palermo ${ }^{63}$. Er ist erst wieder am 3. Februar 1201 in Rom nachzuweisen ${ }^{64}$.

Zwar fehlen für eine tatsächliche Anwesenheit des Kardinallegaten Roffredus de Insula in der zweiten Jahreshälfte 1202 entsprechende Belege ${ }^{65}$, doch ab 1204 scheint es eine dauerhafte Präsenz päpstlicher Legaten auf Sizilien gegeben zu haben. Im April 1204 übertrug Innozenz III. Kardinaldiakon Gerardus von S. Adriano die dauerhafte Legation für das Königreich Sizilien. Er scheint ab 1205 für drei Jahre auf der Insel tätig gewesen zu sein. Dort ist er nach dem 20. Juli 1208 auch gestorben ${ }^{66}$. Doch bereits vor dessen Tod beauftragte Inno-

59 Baethgen (wie Anm. 14) S. 19f.; Maleczek: Papst (wie Anm. 57) S. 93f.; die Nachträge bei DERS.: Zwischen lokaler Verankerung und universalem Horizont. Das Kardinalskollegium unter Innocenz III., in: Innocenzo III. Urbs et Orbis. Atti del Congresso Internazionale, Roma, 9-15 settembre 1998, a cura di Andrea SOMMERLECHNER, 2 Bde., Rom 2003 (Miscellanea della Società Romana di storia patria $44=$ Nuovi Studi Storici 55), hier Bd. 1 S. 102-174, hier S. 134f. Nr. 10, beziehen sich nicht auf Handlungen in oder für Kalabrien oder Sizilien; NeUmanN (wie Anm. 14) S. 125.

60 Vgl. dazu KamP: Kirche (wie Anm. 10) Bd. 2 S. 921; MALECZEK: Papst (wie Anm. 57) S. 94 mit Anm. 257; NeumanN: (wie Anm. 14) S. 135 u. 137.

61 Baethgen (wie Anm. 14) S. 37-41; zur Gesamtsituation der Jahre 1199/1200 vgl. auch STÜRNER: Friedrich II. (wie Anm. 14) S. $93 \mathrm{f}$.

62 So die Ausführungen in einer Legatenurkunde des Cinthius' in AASS Mai Bd. 8 S. 125f., dort heißt es: euntes in Siciliam haberemus transitum per Calabriam, vgl. den Hinweis bei MALeczeK: Papst (wie Anm. 57) S. 106 Anm. 376. Insgesamt vgl. BAETHGeN (wie Anm. 14) S. 23f. u. 37f.

63 Vgl. Maleczek: Papst (wie Anm. 57) S. 106; Kamp: Kirche (wie Anm. 10) Bd. 3 S. $1122 f$.

64 Potthast 1259, ed. Salzburger Urkundenbuch, gesammelt und bearb. von Willibald HauthaleR/Franz Martin, Bd. 3: 1200-1246, Salzburg 1918, Nr. 537 S. 4-7, die Unterschrift auf S. 6.

65 Ohne klare Belege ZimmermanN: Legation (wie Anm. 55) S. 35f. Nr. 24. Der Hinweis auf Potthast 1687 (= Reg. Inn. III., V/37), fuihrt in die Irre, da das Schreiben lediglich die Entsendung bekannt gibt. Auch die weiteren Angaben bei Zimmermann beziehen sich allein auf dieses Stück.

66 Maleczek: Papst (wie Anm. 57) S. 79; Neumann (wie Anm. 14) S. 125f; ungenau ZimmermanN: Legation (wie Anm. 55) S. 36f. Nr. 26. Zu seiner Tätigkeit siehe auch RI 5 Nr. 12326 vom 1. Juli 1208. 
zenz III. zudem den Kardinaldiakon Gregorius de Gualengo mit einer Legation nach Sizilien. Auf der Insel scheint der Legat bereits vor dem Ende des Jahres 1207 angekommen zu sein ${ }^{67} .1209$ reiste er offenbar nach Bari, kehrte jedoch noch im selben Jahr nach Sizilien zurück. Seine Legation scheint bis September 1213 gedauert zu haben, als Innozenz III. ihn abberief ${ }^{68}$.

Die knappe Übersicht zeigt eine spätestens seit 1204 dauerhaft vorhandene Präsenz von Kardinallegaten auf Sizilien. Deren Tätigkeit war zumindest nach Ausweis der Schreiben Innozenz' III. bis zur Mündigkeit Friedrichs II. Ende Dezember 1208 vor allem politischer Natur ${ }^{69}$. Verglichen mit der Epoche vor 1198 hatte sich die Situation damit radikal verändert. Das gilt in besonderem Maße für die Insel Sizilien, die zuvor ein fast „legatenfreier“ Raum gewesen war und sich nun eines besonders intensiven Einsatzes dieses päpstlichen Instrumentes erfreuen konnte. Die plötzlich gesteigerte Legatentätigkeit war zum einen durch die Vormundschaft Innozenz' III. möglich geworden, zum anderen jedoch auch dadurch, dass das apostolische Legationsmandat für Sizilien faktisch erloschen war. Sizilien war damit genau ein Jahrhundert nachdem Urban II. die apostolische Legation an Roger I. übertragen hatte wieder zu einem Raum geworden, der den päpstlichen Legaten offen stand. Rom war auf Sizilien und Kalabrien in dieser Perspektive schlagartig präsent.

\section{Delegaten}

Ebenso wie in Kalabrien lassen sich auch auf Sizilien so gut wie keine Delegationen nachweisen. Zu Beginn des Jahres 1111 beauftragte Paschalis II. Erzbischof Roger von Reggio Calabria zusammen mit Bischof Ansger von Catania, Abt Hubert von S. Eufemia und Lanuinus von S. Maria de Turri den Simonievorwurf gegen Erzbischof Walter von Palermo zu untersuchen. Die delegierten Richter stammten damit alle aus dem Herrschaftsbereich Rogers I., jedoch nur einer aus Sizilien, Ansger, der Bischof des damals noch palermitanischen Suffraganbistums Catania ${ }^{70}$. Damit unterscheidet sich die Situation auf

67 Vgl. dazu Maleczek: Papst (wie Anm. 57) S. 152. Der Legat wird von ZimmerMANN: Legation (wie Anm. 55) S. 41f. Nr. 36 irrig mit Gregorius de Crescentio identifiziert, der jedoch erst ab 1216 als Kardinaldiakon von S. Teodoro nachzuweisen ist; zu diesem vgl. MALECZEK: Papst (wie Anm. 57) S. 183f.; der falschen Zuweisung Zimmermanns folgte jedoch NeumANN (wie Anm. 14) S. 126. Zur Tätigkeit des Gregorius de Gualengo auf Sizilien und in Kalabrien vgl. auch RI 5 Nr. 12347 u. 12352.

68 MaleczeK: Papst (wie Anm. 57) S. 152.

69 Die Mahnung des Papstes an die Empfänger seiner Schreiben, die Legaten zu unterstützen, betonen immer wieder, dass die Tätigkeit der Legaten eine Absicherung der Herrschaft Friedrichs II. zum Ziel hätte. Dieser rote Faden zieht sich auch durch die Mahnschreiben des Papstes an Empfänger im Königreich Sizilien.

70 Vgl. zu dieser Delegation JohrendT: Sonderfall (wie Anm. 2) S. 251. 
Sizilien und in Kalabrien von anderen Regionen Unteritaliens ${ }^{71}$. Und daran scheint sich nach Ausweis der Überlieferung auch im ersten Jahrzehnt nach 1198 nichts grundsätzlich geändert zu haben, da sich nur drei weitere Delegationen über die päpstlichen Register nachweisen lassen ${ }^{72}$ sowie ohne eine systematische Durchsicht des regionalen Materials drei weitere ${ }^{73}$. Doch gerade zu den Delegationen würde eine Aufarbeitung aus dem lokalen Archivmaterial vermutlich noch etliche Delegationen nach 1198 zutage fördern ${ }^{74}$. Dass sich auf der Insel wie auch in Kalabrien nur so wenige Fälle nachweisen lassen, dürfte nicht nur ein Überlieferungsproblem sein, sondern nicht zuletzt auch daran liegen, dass das Instrument der Delegationsgerichtsbarkeit vor Ort mit der königlichen Gerichtsbarkeit in Konkurrenz trat und dabei offensichtlich den Kürzeren zog. Der König und das königliche Gericht, das bei Streitfällen zwischen Geistlichen ausschließlich mit Geistlichen besetzt wurde, waren die erste und nach Ausweis der Quellen auch einzige Stelle, an die sich Geistliche wie Weltliche zur gerichtlichen Klärung eines Streites wandten ${ }^{75}$. An Rom wandten sich die Geistlichen dieser Region dazu offenbar nicht ${ }^{76}$. Das bestens ausgebaute Gerichtswesen im Regno in Kombination mit einer beherrschenden Stellung des normannischen Königs in seinem Königreich schloss gleich-

71 So spricht LOUD: Latin Church (wie Anm. 5) S. 231, davon, dass Eugen III. damit begann, unteritalienische Prälaten zu delegierten Richtern zu ernennen. Die von ihm ebd., S. 242-251, für Unteritalien konstatierte Zunahme von Delegationsprozessen nach dem Konkordat von Benevent (1156) trifft weder auf Kalabrien noch auf Sizilien zu.

72 Die drei päpstlichen Schreiben an Delegaten sind Reg. Inn. III., I/392 (Ebf. Wilhelm von Reggio Calabria u. Bf. Johannes von Cefalù), VI/219 (Bf. Philipp von Martirano, der Abt von Acquaformosa und der Abt von S. Maria di Corazzo) und X/112 (Ebf. Lukas von Cosenza und Bf. Philipp von Martirano). Die Zahl der tatsächlichen Delegationen könnte nach 1198 wesentlich höher gewesen sein, doch ist das Material nicht im selben Maße aufbereitet wie vor 1198 durch IP 10.

73 Die weiteren drei Delegationen sind zu fassen durch KAMP: Kirche (wie Anm. 10), so die 1198 des Erzbischofs Bartholomäus von Palermo im Jahre 1198, ebd., Bd. 3 S. 1121; ebenso Lorenz von Siracusa und Abt Alexander von S. Spirito in Palermo in einem anderen Fall, ebd. S. 1174; Bischof Bernardus von Belcastro 1207 bei der Untersuchung der Wahl des Bischofs Madius von Cerenzia, ebd. Bd. 2 S. 894.

74 Zur Problematik der Quellenaufarbeitung für die päpstliche Delegationsgerichtsbarkeit siehe den Beitrag von Harald Müller in diesem Band.

75 Zur Konkurrenz der Delegationsgerichtsbarkeit mit den regulären kirchlichen Gerichten sowie der weltlichen Gewalt vgl. allg. Harald MüLLER: Entscheidung auf Nachfrage. Die delegierten Richter als Verbindungsglieder zwischen Kurie und Region und Gradmesser päpstlicher Autorität, in: JOHRENDT/MülLER: Zentrum (wie Anm. 2) S. 109-131, hier S. 127. Zu konkreten Streitfällen unter Wilhelm II. vgl. SCHLICHTE: König (wie Anm. 9) S. 135-138. Siehe dazu auch unten bei Anm. 81.

76 Vgl. dazu bis 1198 Jochen JOHRENDT: Italien als Empfängerlandschaft (1046-1198): ein Vergleich aus der Perspektive des Urkundenalltags in Ligurien, Umbrien und Kalabrien, in: Herbers/Johrendt: Papsttum (wie Anm. 16), S. 183-213, hier S. $200 f$. zu Delegationen in Ligurien. 
sam die Lücke, in der das Delegationswesen in anderen Regionen Europas zur Anwendung kam. Dies belegt etwa das Beispiel des Erzbischofs Carus von Monreale, der 1196 vor dem Hof der Kaiserin Konstanze gegen den Abt von S. Maria del Patir prozessierte ${ }^{77}$.

\section{Umsetzung des kanonischen Rechts}

Hinsichtlich der Umsetzung des kanonischen Rechts auf Sizilien und in Kalabrien sind Aussagen nur mit äußerster Vorsicht zu treffen. Ist allgemein bemerkt worden, dass Italien mit dem Reformpapsttum zu einem Zentrum der Kanonistik wurde ${ }^{78}$, so scheint dies nicht für Kalabrien und Sizilien zu gelten, die vor der Eroberung durch die Normannen dem griechisch-byzantinischen sowie muslimischen Kulturkreis angehörten, so dass Rechtsschulen oder ähnliche institutionelle Träger des kanonischen Rechts, die überregionale Bedeutung besessen hätten, fehlten ${ }^{79}$. Auch die Zahl der nachweisbaren Anfragen an Rom aus diesen Regionen ist - vor allem verglichen mit England und dem Nordwesten Frankreichs - äußerst gering ${ }^{80}$. Dies ist wohl vor allem durch die hohe Effektivität des königlichen Gerichtswesens zu erklären, wie es spätestens seit Wilhelm II. deutlich zu fassen ist ${ }^{81}$. Wilhelm II. erklärte sich in einem Gesetz (das in mehreren Mandaten zwischen 1170 und 1175 auch konkrete Anwendung fand) - entgegen dem privilegium fori, auf dessen Gültigkeit die Päpste in anderen Regionen stets pochten - auch für die Aburteilung von straffälligen Geistlichen zuständig. Eine Regelung, die unter Wilhelm II. an der Kurie

77 Vgl. Kamp: Kirche (wie Anm. 10) Bd. 3 S. 1192.

78 Vgl. etwa zusammenfassend Wilfried HARTMANN: Der Investiturstreit, München ${ }^{3} 2007$ (Enzyklopädie Deutscher Geschichte 21) S. 60f. Zur Bedeutung der italienischen Dekretisten vgl. jüngst Kenneth Pennington/Wolfgang P. MüLleR: The Decretists. The Italian School, in: The History of Medieval Canon Law in the Classical Period, 1140-1234. From Gratian to the Decretals of Pope Gregory IX, hg. v. Wilfried Hartmann/Kenneth Pennington, Washington, D.C. 2008 (History of Canon Law 6), S. 121-173, die in der Reihe der Kanonisten unter den aus Süditalien stammenden Personen lediglich auf den aus einem Beneventaner Geschlecht stammenden Petrus Beneventanus hinweisen, S. 142. Zu diesem vgl. MALECZEK: Papst (wie Anm. 57) S. 172-174.

79 Das Fehlen von „Bildungszentren“ konstatierte bereits Norbert KAMP: Die Bischöfe Siziliens in der Normannenzeit: ihre soziale Herkunft und ihr geistlicher Bildungsweg, in: Abhandlungen der Braunschweigischen Wissenschaftlichen Gesellschaft 45 (1995) S. 81-103, hier S. 105, in Zusammenhang mit fehlenden Ausbildungsstätten für den bischöflichen Nachwuchs des Königreichs Sizilien.

80 Siehe dazu unten bei Anm. 207.

81 Vgl. dazu Schlichte: König (wie Anm. 9) S. 43-56. 
offenbar keine Proteststürme hervorbrechen ließ und die schließlich in die Konstitutionen von Melfi Eingang fand ${ }^{82}$.

Doch nicht nur bei der Verbreitung wichtiger Konzilsbeschlïsse wie etwa dem Dritten Lateranum muss man für Kalabrien und Sizilien Fehlanzeige erstatten $^{83}$. Für eine begrenzte Geltung dieser in den beiden Regionen sehr schlecht überlieferten römischen Normen spricht auch die Klage Alexanders III. gegenüber König Wilhelm II., dass dieser für die rasche Wiederbesetzung von vakanten Bischofsstühlen sorgen solle ${ }^{84}$. Neben der Sorge um die Einhaltung römischer Normen waren es sicherlich auch die vom sizilischen König in der Zeit der Vakanz beanspruchten Einkünfte der Kirche, die Alexander III. zu einer Intervention trieben. Dass dies notwendig wurde, spricht nicht für eine offenbar nur begrenzte Geltung römischer Normen im Regno ${ }^{85}$. Das gilt vor allem ab der Zeit Wilhelms II. auch für das geistliche Gerichtswesen. Denn ab dieser Zeit sitzt einer geistlichen Kurie am Königshof, an der Streitfälle zwischen Geistlichen verhandelt wurden, auch ein Großhofjustiziar bei, ein offizieller Beamter des Königs, wodurch das königliche Hofgericht auf der Insel Sizilien zu der entscheidenden und zugleich an den königlichen Hof gekoppelten Instanz wurde ${ }^{86}$. Zudem beanspruchte der König eine allgemeine Appellationsgerichtsbarkeit, für die sich rasch ein System der von diesem und seinen Familiaren delegierten Richtern ausgebildet hatte - die funktional auch die Aufgaben der päpstlichen Delegationsgerichtsbarkeit übernahmen ${ }^{87}$. Auch wenn die Dimensionen schwer einzuschätzen sind, so sprechen die wenigen Nachweise, die päpstliche Delegaten in den Quellen Kalabriens und Siziliens hinterlassen haben, dafür, dass die königliche Gerichtsbarkeit offenbar nicht nur ein klare Alternative zu der in anderen Teilen Europas intensiv genutzten päpstlichen Delegationsgerichtsbarkeit war, sondern für die überragende Mehr-

82 Die Konstitutionen Friedrichs II. für das Königreich Sizilien, hg. v. Wolfgang STÜRNER, Hannover 1991 (MGH Const. Supplementum 2), I 45 S. 204. Zu den Regelungen unter Wilhelm II. und deren Anwendung in Mandaten vgl. auch ENZENSBERGER: Wilhelm (wie Anm. 8) S. 428f; Loud: Control (wie Anm. 12) S. 154.

83 So die freundliche Auskunft von Uta-Renate Blumenthal.

84 Edition des Briefes bei Samuel LoEWENFELD: Epistolae pontificum Romanorum ineditae, Leipzig 1885, Nr. 279 S. 159f. Alexander III. bezog sich mit seiner Forderung auf geltendes kanonisches Recht. Das Dritte Laterankonzil legte in seinem achten Kanon fest, dass alle kirchlichen Ämter innerhalb von sechs Monaten zu besetzen seien, vgl. Lateranum III c. 8, Conciliorum oecumenicorum decreta, curantibus Josepho ALBERIGO et alteris consulante Huberto JEDIN, Bologna ${ }^{3} 1973$, S. 191 Z. 26-29.

85 So Hubert Houben: Die Abtei Venosa und das Mönchtum im normannischstaufischen Süditalien, Tübingen 1995 (Bibliothek des Deutschen Historischen Instituts in Rom 80), S. 67.

86 Vgl. dazu Schlichte: König (wie Anm. 9) S. 43-47, dort auch weitere Literatur.

87 Vgl. dazu ebd., S. 45f. Zum Ausbau und der offenbar auch sehr guten Akzeptanz der königlichen Verwaltung sowie des königlichen Gerichtswesens unter Wilhelm II. vgl. auch Hiroshi TAKAYAma: The administration of the Norman kingdom of Sicily, Leiden u. a. 1993 (The medieval mediterranean 3), S. 143-162. 
heit der Streitparteien offenbar attraktiver war. Das blieb offenbar auch nach 1198 so, denn das Eingreifen Innozenz' III., der zumal während seiner Regentschaft im Königreich offenbar immer wieder die Einhaltung kanonischer Grundsätze einforderte, traf beispielsweise hinsichtlich der Prozessordnung in Neapel auf Widerstand ${ }^{88}$.

\section{Exemtion und Papstschutz}

Exemtionen von Klöstern lassen sich auf Sizilien nicht nachweisen - abgesehen von Monreale, das jedoch insofern ein Sonderfall ist, da offenbar bereits bei der Gründung geplant war, das Kloster zum Erzbistum zu erheben. Alexander III. eximierte das Bistum auf Bitten König Wilhelms II., an den sich die entsprechende Urkunde des Papstes auch richtete ${ }^{89}$. Zugleich stellte er das Kloster unter den päpstlichen Schutz. Ausgangspunkt der Exemtion sowie der Verleihung des päpstlichen Schutzes war damit ähnlich wie im Falle des Klosters SS. Trinità in Kalabrien (das wie Monreale eine besondere Nähe zu den Hauteville aufwies) der König gewesen, der den Papst um Exemtion und Schutz bat, vermutlich nicht zuletzt um seine Gründung vor den Eingriffen des Diözesanbischofs zu schützen ${ }^{90}$.

Doch stellt Monreale gerade aufgrund seiner Gründungsgeschichte eine absolute Ausnahme im Vergleich zu den anderen sizilischen Bistümern dar. Der einzige weitere Eingriff in die Metropolitanstruktur der Insel, bei der es zur verstärkten Anbindung eines Bistums an Rom kam, ist die Herauslösung Cefalùs aus dem Verband von Messina unter Alexander III. Er erklärte, dass das seinerzeit von Anaklet II. ins Leben gerufene und Messina unterstellte Cefalù nunmehr direkt dem päpstlichen Stuhl unterstehe, mithin exemt sei ${ }^{91}$, was schließlich auch Clemens III. bestätigte ${ }^{92}$. Doch dies ist der einzige Eingriff, der als die Exemtion eines bestehenden Bistums zu werten ist, da die Exemtion

88 Vgl. dazu die Bemerkungen bei Baethgen (wie Anm. 14) S. 115 mit Anm. 1.

89 IP 10 S. 274 Nr. 1 u. S. 275 Nr. 2.

$90 \mathrm{Zu}$ den Motiven Wilhelms II. für die Gründung Monreales vgl. zusammenfassend SCHLICHTE: König (wie Anm. 9) S. 186-196, die auch der älteren These entgegentritt, dass die Gründung Monreales die wirtschaftlichen Ressourcen des Königreichs überbeansprucht habe. Zur Bistums- und Klosterexemtion siehe die Lotte Kéry und Matthias Schrör in diesem Band. Zur Exemtion von Klöstern in Italien vgl. Volkert PFafF: Die päpstlichen Klosterexemtionen in Italien bis zum Ende des zwölften Jahrhunderts. Versuch einer Bestandsaufnahme, in: ZR GKanAbt 72 (1986) S. 76-114, bes. S. 78-89; an französischen Beispielen erarbeitet Ludwig FALKENSTEIN: La papautè et les abbayes françaises aux $\mathrm{XI}^{\mathrm{e}}$ et XII ${ }^{\mathrm{e}}$ siècles. Exemption et protection apostolique, Paris 1997.

91 IP 10 S. 364 Nr. 2. Innozenz II. hatte die Erhebung Cefalùs zum Bistum durch Anaklet II. nicht anerkannt, zu den Folgen vgl. Loud: Latin Church (wie Anm. 5) S. 229.

92 IP 10 S. 366 Nr. 7. Zur Bestätigung der Exemtion unter Honorius III. vgl. Potthast $6967 \mathrm{a}$. 
des Bistums Monreale auf der Exemtion des Klosters aufbaut. Obwohl die Exemtion aus dem Privileg Alexanders III. abzuleiten ist, scheint die Rechtsstellung nicht allgemein anerkannt gewesen zu sein ${ }^{93}$. Denn Lucius III. forderte zwölf Jahre nach der Exemtion durch Alexander III. wiederum den schuldigen Gehorsam des Bischofs von Cefalù gegenüber dem Erzbischof von Messina ${ }^{94}$, was in das Bild einer in Rom ausgesprochenen Exemtion, die ein bewusstes Mittel zur Romanbindung war, nicht recht passen will ${ }^{95}$. Dieser Eindruck wird noch dadurch verstärkt, dass es Alexander III. bei dem Versuch, seine Weihekompetenzen bei den sizilischen Bistümern auszuweiten, scheiterte ${ }^{96}$. Vor diesem Hintergrund ist die Exemtion Monreales und Cefalùs weniger als ein Mittel der Romzentrierung zu interpretieren, als vielmehr ein Mittel, um eine kirchliche Institution vor Ort vor Eingriffen anderer kirchlicher Institutionen zu schützen - ohne dabei der Zentralisierung in die Arme zu spielen.

War die Exemtion ein offenbar selten von sizilischen Kirchen begehrter Rechtstatus, so ist die Verleihung des Papstschutzes wesentlich häufiger zu fassen ${ }^{97}$. Er ist insgesamt $21 \mathrm{mal}$ nachzuweisen, erstmals in einer Urkunde Urbans II. von 1091 für das Kloster S. Bartolomeo in Lipari, das die Grundlage für das auf Verlagen Rogers II. von Anaklet II. 1131 geschaffene Bistum Lipari-Patti bildete ${ }^{98}$. Einzig bei dem Kloster S. Georgii in Cavea Grateriae ist eine

93 Der «Liber Censuum» macht zu den sizilischen Bistümern letztlich keine belastbaren Aussagen. Bei Otto VEHSE: Bistumsexemptionen bis zum Ausgang des 12. Jahrhunderts, in: ZR GKanAbt 26 (1937) S. 86-160, wird das Bistum Cefalù unter den 30 von ihm behandelten Bistümern nicht erwähnt.

94 RI 4/4/4/1, Nr. 483.

95 So betonte PACAUT (wie Anm. 47) S. 58f., dass die Exemtion ein verstärkt unter Alexander III. eingesetztes Instrument gewesen sei, dass dazu gedient habe, die unteritalienische Kirche an den Papst zu binden. Lucius III. habe diese Linie fortgesetzt.

96 Siehe dazu unten bei Anm. 150.

97 Eine grundlegende Untersuchung zum Papstschutz - zumal für das 12. und 13. Jahrhundert - scheint nach den neueren Forschungsergebnissen dringend geboten, vgl. dazu etwa die Ergebnisse von Barbara H. RosenWEIN: Negotiating Space. Power, Restraint, and Privileges of Immunity in Early Medieval Europe, Ithaca 1999, etwa am Beispiel Clunys S. 165-172; im europäischen Vergleich für die 150 Jahre vor 1046 Jochen JOHRENDT: Papsttum und Landeskirchen im Spiegel der päpstlichen Urkunden (896-1046), Hannover 2004 (MGH Studien und Texte 33), S. 147-167, 200-208, 234-237, 253-255 u. 264-267; DERS.: La protezione apostolica alla luce dei documenti pontifici (896-1046), in: Bullettino dell'Istituto storico italiano per il Medio Evo 107 (2005) S. 135-168.

98 Die Urkunde Urbans II., der seinerzeit eine Erhebung zum Bistum noch abgelehnt hatte, ist IP 10 S. 359 Nr. 1. Vgl. zur Urkunde Urbans II. und der Erhebung unter Anaklet II. CASPAR: Gründungsurkunden (wie Anm. 1) S. 99-101; HOUBEN: Roger II. (wie Anm. 3) S. 59; zu den Versuchen Innozenz' II., die Erhebung auch faktisch zu beseitigen LOUD: Latin Church (wie Anm. 5) S. 227; zur Geschichte des Bistums jüngst Luciano CATALIOTO: Il Vescovato di Lipari-Patti in età normanna (1088-1194). Politica, economia, società inuna sede monastico-episcopale della Sicilia (Collana di testi e studi storici 12), Messina 2007, S. 77-91. 
Privilegienkette zu vermuten, die auf Innozenz II. zurückgeht und über Lucius II. bis zu Lucius III. reicht ${ }^{99}$. Alle weiteren Papstschutzprivilegien wurden jedoch erst nach 1169 ausgestellt, so unter Alexander III. für das Kloster Monreale ${ }^{100}$, die Bistümer Catania ${ }^{101}$ und Siracusa ${ }^{102}$ sowie das Kloster SS. Salvatore in Messina ${ }^{103}$. Unter Lucius III. folgte das - aus dem unter päpstlichem Schutz stehenden Kloster hervorgegangene - Erzbistum Monreale ${ }^{104}$. Abgesehen von S. Bartolomeo und S. Georgii ist damit für keine Kirche Siziliens ein Papstschutzprivileg überliefert. Diese setzen erst 1169 und damit mit Alexander III. ein.

Der Befund für Sizilien, vor allem die chronologische Verteilung der Papstschutzprivilegien, stellt sich anders als für Kalabrien dar. Dort lassen sich 29 Urkunden nachweisen, in denen die Päpste den Papstschutz gewähren. Die Differenz von acht Urkunden sollte nicht überbewertet werden. Aussagekräftig scheit mir hingegen der Zeitpunkt, zu dem die Papstschutzprivilegien ausgestellt wurden. Kann man holzschnittartig für Sizilien sagen, dass der Papstschutz dort ein Phänomen ist, das erst mit Alexander III. auf der Insel Einzug hielt, so lassen sich für Kalabrien etliche Privilegien aus der Zeit davor fassen. So wurde Reggio Calabria die protectio apostolica bereits von Gregor VII. und Eugen III. urkundlich bestätigt ${ }^{105}$. Auch das Bistum Cassano Ionio erhielt den Papstschutz unter Paschalis II. ${ }^{106}$, die Kirche S. Salvatore iuxta villam S. Martini sowie das Kloster San Filippo in Gerace von Urban II. ${ }^{107}$, San Giuliano di Rocca Fallucca von Paschalis II. ${ }^{108}$, Sambucina von Eugen III. ${ }^{109}$ und das neu zu gründende Kloster S. Maria von Botrano von Innozenz III. ${ }^{110}$ Das herausragende Beispiel, das von Paschalis II. bis zu Clemens III. regelmäßig von den

\footnotetext{
99 IP 10 S. 366 Nr. ${ }^{\star} 1,{ }^{\star} 2$ u. 3.

100 IP 10 S. 274 Nr. $1-3$.

101 IP 10 S. 292 Nr. 25 u. 26.

102 IP 10 S. 318 Nr. 73.

103 IP 10 S. 347 Nr. 1.
}

104 IP 10 S. 276 Nr. 8, S. 277 Nr. 9 u. S. 278 Nr. 11. RI 4/4/4/1 Nr. 479. Vgl. dazu auch die Nachurkunden unter Clemens III., IP 10 S. 279f. Nr. 16-19 u. 21; sowie die Nachurkunde unter Innozenz III. in Reg. Inn. III., I/316 für Ebf. Carus von Monreale. Zur letztgenannten Urkunde vgl. KamP: Kirche (wie Anm. 10) Bd. 3 S. 1192.

105 IP 10 S. 20 Nr. ${ }^{\star} 11$ u. ${ }^{\star} 19$. Darauf folgt die Verleihung unter Alexander III. in IP 10 S. 23 Nr. 20.

106 IP 10 S. 27 Nr. 2.

107 IP 10 S. 48 Nr. 1 u. S. 54 Nr. ${ }^{1}$.

108 IP 10 S. 84 Nr. 5.

109 IP 10 S. 96 Nr. 2, es folgen Privilegien Alexanders III., Clemens' III. und Cölestins III., IP 10 S. 97 Nr. ${ }^{\star} 3,6$ u. S. 98 Nr. 8.

110 Vgl. Reg. Inn. III., VII/149. Es ist jedoch unklar, ob diese Gründung, die von Fiore aus erfolgen sollte, tatsächlich vollzogen wurde. Wenn ja, so scheint das Kloster jedoch keine lange Lebensdauer gehabt zu haben, vgl. dazu Francesco Russo: Gioacchino da Fiore e le fondazione florensi in Calabria, Napoli 1959 (Collana storica 1), S. 174. 
Päpsten den Papstschutz verliehen erhielt, ist SS. Trinità in Mileto, ein Kloster, das seit den Tagen Rogers I. in besonderer Nähe zu den normannischen Herrschern stand ${ }^{111}$. Dem stehen zwar acht Empfänger gegenüber, die erst ab dem Pontifikat Alexanders III. den Papstschutz erhalten hatten ${ }^{112}$. Doch ist nicht zu verkennen, dass die Papstschutzverleihungen bereits vor Alexander III. als gängige Praxis bezeichnet werden können. Das Beispiel des Klosters SS. Trinità zeigt zudem, dass diese Verleihungen offenbar in Kalabrien auch von den normannischen Herrschern gewollt wurden, der Herrscher in diesem Fall die Verleihungen des Papstschutzes nicht behinderte.

Ein deutlicher Unterschied zwischen Kalabrien und Sizilien tritt bei der Exemtion zutage. Waren auf Sizilien allein Monreale und Cefalù mit der Exemtion ausgestattet worden, so lassen sich in Kalabrien zwei Bistümer und drei Klöster als Empfänger von Exemtionsprivilegien fassen ${ }^{113}$. Hinzu kommt noch ein Kloster, bei dem sich die Exemtion als Fälschung erweist, was wiederum ein Indiz dafür ist, dass man in dieser Region um die Exemtion so sehr bemüht war, dass man sogar zum Mittel der Fälschung griff ${ }^{14}$. Anders als auf

111 Der Papstschutz wurde dem Kloster von Paschalis II., Calixt II., Innozenz II., Eugen III., sowie zweimal von Alexander III. und Clemens III. verliehen. IP 10 S. 145 Nr. 3, S. 146 Nr. 8, S. 147 Nr. ${ }^{\star} 9$ u. 11, S. 148 Nr. 14, S. 149 Nr. 15 u. ${ }^{\star} 17$.

112 Im Einzelnen sind dies unter Alexander III. das Kloster S. Maria del Carrà im Bistum Nicastro (IP 10 S. 35 Nr. 2), das Bistum Tropea (IP 10 S. 39 Nr. 2), S. Maria de Turri (IP 10 S. 73 Nr. 18, und nochmals unter Cölestin III., ebd. S. 75 Nr. ^23) und das Bistum Catanzaro (IP 10 S. 82 Nr. 14). - Unter Lucius III. erhielt das Erzbistum Santa Severina den Papstschutz (IP 10 S. 127 Nr. 2 = RI 4/4/4/1 Nr. 1009). - Unter Clemens III. S. Maria di Bagnara im Bistum Mileto (IP 10 S. 158 Nr. 1, bestätigt durch Cölestin III., ebd. S. 159 Nr. 3). - Unter Cölestin III. folgen das Bistum Bisignano (IP 10 S. 94 Nr. 1) und das Kloster S. Maria del Patir (IP 10 S. 106 Nr. ${ }^{*}$ 3).

113 Bei den beiden Bistümern handelt es sich um Cassano Ionio, das zwei Privilegien erhielt, IP 10 S. 27 Nr. 2-3, und Mileto, das insgesamt sechs Exemtionsprivilegien er-

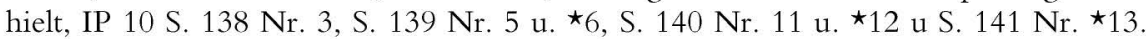
Unter den drei Klöstern erhielt S. Maria Mattina zwei Exemtionsprivilegien, IP 10 S. 91 Nr. 2 u. ${ }^{*}$; SS. Trinità in Mileto erhielt acht echte Exemtionsprivilegien, IP 10 S. 145 Nr. 1 u. 3, S. 146 Nr. 8, S. 147 Nr. *9, S. 147 Nr. 11, S. 148 Nr. 14, S. 149 Nr. 15 u. $\star 17$; ferner ist für dieses Kloster auch eine Fälschung nachzuweisen, IP $10 \mathrm{~S} .147 \mathrm{Nr}$. $\dagger 10$. Als Exemtionsprivilegien sind wohl auch die vier Urkunden für S. Giuliano di Rocca Fallucca zu werten, IP 10 S. 84 Nr. 5- 8.

114 Dabei handelt es sich um die beiden Stücke für die Zisterze S. Maria Sambucina IP 10 S. 97 Nr. †5 u. S. 98 Nr. †7. Zu S. Maria Sambucina vgl. Theo KölzER: La monarchia normanno-svevo e l'Ordine Cistercense, in: I cistercensi nel mezzogiorno medioevale, Atti del Convegno internazionale di studio in occasione del IX centenario della nascita di Bernardo di Clairvaux (Martano - Latino - Lecce, 25-27 febbraio 1991), hg. v. Hubert Houben/Benedetto VeTERE, Lecce 1994, S. 91-116; sowie HoubeN: Venosa (wie Anm. 85) S. 76f. Zu den italienischen Zisterzen vgl. jüngst auch Rinaldo COMBA: I monaci bianchi e il papato in Italia: caratteri e metamorfosi delle identità e idealità cistercensi nella prima metà del XII secolo, in: HERBERS/ JOHRENDT: Papsttum (wie Anm. 16) S. 515-555. 
Sizilien ist die Exemtion damit ein in Kalabrien häufig erbetener Rechtszustand. Im Falle des Bistums Mileto sowie des dortigen Klosters SS. Trinità sind die Normannenherrscher sicherlich die treibenden Kräfte gewesen, die für die Exemtion sorgten ${ }^{115}$. Und anders als auf Sizilien waren diese Exemtionen keine Neuerung der Kirchenstruktur, die erst unter Alexander III. eingeführt worden war. Fast alle kalabrischen Exemtionen haben ihren Ursprung noch im 11. Jahrhundert ${ }^{116}$.

Wieso war man in Kalabrien um Exemtionen, um eine Herauslösung aus dem normalen Metropolitanverband und unmittelbare Unterstellung unter Rom, interessiert und auf Sizilien nicht? Ausschlaggebend dürften dafür strukturelle Gründe in den Regionen einerseits und andererseits eine Veränderung im Verhältnis von Normannenherrschern zu Rom gewesen sein. Zumindest im Fall von Mileto dürften die Hauteville die treibende Kraft gewesen sein. Die Exemtion in ihrer römischen Ausprägung dürfte den kalabrischen Kirchen jedoch nicht von Anfang an bekannt gewesen sein, doch durch die Autokephalie etlicher griechischer Bistümer war ihnen ein vergleichbarer Rechtsstatus aus der griechischen Kirche bestens bekannt ${ }^{117}$. Es liegt daher nahe, das im Vergleich zu Sizilien in Kalabrien verstärkte Bestreben um eine Exemtion vor diesem Hintergrund $\mathrm{zu}$ betrachten. Auf Sizilien konnte man hingegen auf derartige Erfahrungen nicht aufbauen.

\section{Ad-limina Besuche und Pallien}

Eine Vielzahl der für sizilische Empfänger ausgestellten Urkunden ist den Pallien gewidmet. Dies hängt zum einen mit der neu gegründeten Kirchenstruktur zusammen, die bei Messfeierlichkeiten - bei der genuin priesterlich, bischöflichen Aufgabe - in Form des Palliums zum Ausdruck kommen konnte. Die Forschungen von Zotz haben jedoch ebenfalls gezeigt, dass der Kontakt und der Austausch zwischen den Bischöfen Voraussetzung dafür ist, dass sich Bischöfe um eine Vermehrung der Tage bemühten, an denen sie das Pallium

115 Vgl. BeCKeR: Graf (wie Anm. 1) S. 162-166 u. 191f. Dass die Exemtionen in der Regel auf die Hauteville zurückzuführen sind, betont auch LOUD: Latin Church (wie Anm. 5) S. 213.

116 Allein die Exemtion von S. Giuliano di Rocca Fallucca ist nicht vor 1117 zu fassen, vgl. IP 10 S. 84 Nr. 5.

117 Zur Situation der kalabrischen Bistümer vgl. Vera vON FALKENHAUSEN: Untersuchungen über die byzantinische Herrschaft in Süditalien vom 9. bis ins 11. Jahrhundert, Wiesbaden 1967 (Schriften zur Geistesgeschichte des östlichen Europa 1), S. 148151; vgl. auch in Bezug auf Apulien und das bewusst von Byzanz eingesetzte Mittel der Autokephalie Axel BAYER: Spaltung der Christenheit. Das sogenannte Morgenländische Schisma von 1054, Köln u. a. 2002 (Beih. zum AK 53), S. 66f.; zur Autokephalie allg. Lorenzo PERRONE: Art. Autokephalie, in: Lex MA 1 (1980) Sp. $1269 f$. 
tragen durften ${ }^{118}$. Erst der enge Kontakt der Bischöfe untereinander machte derartige Regelungen sinnvoll, da sie nur dann als ein Element der Konkurrenz zwischen den einzelnen Bistümern eingesetzt werden konnten. Die Nachfrage nach Palliumurkunden ist daher gleichsam ein Indikator für den Zusammenhalt einer Landeskirche, für die Intensität des Austausches in dieser, jedoch ebenso Ausdruck einer offenen Situation, in der die Metropolitanstruktur noch beweglich ist und das Pallium die Absicherung eines Rechtsstatus bedeutet ${ }^{119}$.

Vor diesem Hintergrund verwundert es nicht, dass sich für Sizilien viele Palliumurkunden nachweisen lassen, da die Metropolitanstruktur hier erst im Entstehen war und selbst nach einer Phase der Verfestigung 1183 durch die Erhebung Monreales zum Erzbistum in unmittelbare Nähe zum Sitz des Erzbischofs von Palermo nochmals verändert wurde ${ }^{120}$. Nicht weniger als 15 Nummern der Italia Pontificia beziehen sich auf Regelungen zum Pallium für sizilische Empfänger. Bis 1166 sind allein zwei Palliumurkunden für den Palermitaner Erzbischof überliefert ${ }^{121}$. Die Pallien besaßen offenbar auch im Selbstverständnis der Palermitaner Metropoliten und ihres königlichen Herrn, Rogers II., einen beachtlichen Wert, denn der sizilische König wandte sich 1150 persönlich an Eugen III. und bat diesen um ein Pallium für den Elekten Hugo von Palermo ${ }^{122}$. Die restlichen Palliumurkunden für andere Bistümer

118 Thomas ZOTZ: Pallium et alia quaedam archiepiscopatus insignia. Zum Beziehungsgefüge und zu Rangfrage der Reichskirchen im Spiegel der päpstlichen Privilegierung des 10. und 11. Jahrhunderts, in: Festschrift für Berent Schwineköper zu seinem siebzigsten Geburtstag, hg. v. Helmut MAURER/Hans PATZE, Sigmaringen 1982, S. 155-175. Für die Ottonen- und frühe Salierzeit im europäischen Vergleich auch JOHRENDT: Papsttum (wie Anm. 97), S. 220-225, 231f. u. 256f.

$119 \mathrm{Vgl}$. dazu für das 10. und die erste Hälfte des 11. Jahrhunderts vor allem für die Kirche im Reich nördlich der Alpen im Gegensatz zur französischen Kirche JOHRENDT: Papsttum (wie Anm. 97) S. 231f., sowie Matthias SCHRÖR: Metropolitangewalt und papstgeschichtliche Wende, Husum 2009 (Historische Studien 494), S. 76-80.

120 Auf diese hohe Dynamik wies bereits VeHSE (wie Anm. 93) S. 120-127, hin. Vgl. auch CASPAR: Gründungsurkunden (wie Anm. 1) S. 97-103, in den Wertungen bisweilen mit Vorsicht zu genießen; zur Weiterentwicklung der sizilischen Kirchenorganisation im 12. Jahrhundert vgl. auch KAMP: Episkopat (wie Anm. 25) S. 110f.; LOUD: Latin Church (wie Anm. 5) S. 234f.

121 Es handelt sich um eine Urkunde zugunsten des Erzbischofs Alcerius von Palermo aus der Kanzlei Gregors VII., IP 10 S. 229 Nr. 20; und für Petrus von Palermo, ausgestellt von Calixt II., IP 10 S. 230 Nr. 24.

122 IP 10 S. 231 Nr. *26. Es ist durchaus denkbar, dass die Bitte um das Pallium in Verbindung mit den Vorbereitungen für eine geplante Herrscherweihe Wilhelms I. stand. Zwar wurde Wilhelm schließlich in einer kirchlichen Zeremonie erhoben, doch Roger II. krönte seinen Sohn offenbar selbst, vgl. HoubEN: Roger II. (wie Anm. 3) S. 102f. Dennoch war für die Zeremonie ein mit allen Zeichen seiner erzbischöflichen Würde ausgestatteter Metropolit von Palermo vermutlich auch in den Augen Rogers II. von Nöten, um ihr einen würdigen und makellosen Rahmen zu geben, zumal der Normanne 
setzen folglich erst mit Alexander III. ein, für den bis 1171 derartige Privilegien für Messina, Catania, Palermo und Siracusa nachzuweisen $\operatorname{sind}^{123}$. Die weiteren Privilegien verteilen sich unauffällig im restlichen Untersuchungszeitraum und sind teilweise durch die Erhebung Monreales zum Erzbistum bedingt, gleichsam eine Folge der veränderten Kirchenstruktur auf der Insel ${ }^{124}$. Für das Jahrzehnt nach 1198 lässt sich keine weitere Palliumurkunde nachweisen.

Natürlich ist auch in diesem Jahrzehnt mit einem entsprechenden Überlieferungsverlust zu rechnen, da wir insgesamt von sieben Erzbischöfen wissen, dass sie das Pallium erhalten haben, ohne dass sich eine entsprechende Urkunde überliefert hätte. In drei oder vielleicht sogar fünf Fällen erhielten die Erzbischöfe das Pallium direkt aus den Händen des Papstes: Johannes von Catania, der von Alexander III., und Wilhelm von Monreale, der von Lucius III. geweiht worden war, erhielten es im Anschluss an ihre Weihe ${ }^{125}$. Erzbischof Jakobus von Reggio Calabria holte sich sein Pallium vor dem 17. August 1199 in Rom von Innozenz III. persönlich $\mathrm{ab}^{126}$. Unklar sind die beiden Fälle der Erzbischöfe Richard Palmer und Berardus von Messina. Zwar wurde bei Richard Palmer eine persönliche Entgegennahme des Palliums von Alexander III. im April 1169 vermutet, doch fehlt für diese These eine entsprechende Quellengrundlage $^{127}$. Wo Berardus von Messina 1198 sein Pallium in Empfang nahm, ist hingegen völlig unklar ${ }^{128}$. Wiederum in den Pontifikaten Alexanders III. und Innozenz' III. sind zwei Palermitaner Erzbischöfe zu fassen, denen das Pallium zugesandt wurde: im Jahre 1169 Erzbischof Walter von Palermo, der es durch

beim Papst nicht um eine Belehnung Wilhelms gebeten hatte und die Herrschaftsübertragung damit formale Mängel aufwies.

123 Für Messina IP 10 S. 340 Nr. 26; für Catania IP 10 S. 292 Nr. 25 u. 26; für Palermo IP 10 S. 232 Nr. 32; für Siracusa IP 10 S. 318 Nr. 73.

124 Das gilt für die Urkunden für den Erzbischof von Monreale, IP 10 S. 276 Nr. 7 u. S. 279 Nr. 15, ebenso wie für das Parallelschreiben zu IP 10 S. 276 Nr. 7 an den Bischof von Catania. Denn dessen Nachfolger wurde der Gebrauch des Palliums untersagt, IP 10 S. 293 Nr. 27. Dasselbe gilt für das Schreiben an den Bischof von Siracusa unter Clemens III., IP 10 S. 319 Nr. 76.

125 Die Weihen werden in den entsprechenden Palliumprivilegien angesprochen, vgl. IP 10 S. 292 Nr. 25 und IP 10 S. 276 Nr. ${ }^{\circ} 6$ (= RI 4/4/4/1 Nr. 474), vgl. dazu auch KAMP: Kirche (wie Anm. 10) Bd. 3 S. 1187.

126 Das ist dem Schreiben Reg. Inn. III., II/165 zu entnehmen, in dem Innozenz III. Klerus und Volk den neugewälten Erzbischof $I$ (vermutlich Jacobus) empfiehlt und darauf hinweist, dass er das Pallium aus den Händen des Papstes persönlich empfangen habe.

127 Zwar formuliert KAMP: Kirche (wie Anm. 10) Bd. 3 S. 1016, dass Richard in Benevent von Alexander persönlich geweiht worden sei und verweist dazu auf IP 10 S. $318 f$. Nr. 73, doch das ist dem Privileg nicht zu entnehmen, da es nur die Norm formuliert, dass der Erzbischof von Messina vom Papst persönlich zu weihen sei.

128 Die Nachricht beruht auf Potthast nach 146. Der dort geäußerte Fälschungsverdacht ist nach KAMP: Kirche (wie Anm. 10) Bd. 3 S. 1020 Anm. 74, unbegründet. 
den Kardinalpresbyter Johannes von S. Anastasia erhielt ${ }^{129}$, und wohl nach 1202 Petrus von Palermo, worüber die «Gesta Innocentii» berichten ${ }^{130}$.

Pallien nehmen daher offenbar nicht nur bei der Überlieferung der mit ihnen verbundenen Privilegien für die sizilische Kirche einen wichtigen Platz ein, sondern auch die Nachrichten über den Empfang der Pallien sind erstaunlich dicht. Mit anderen Worten, die Pallien fanden in der Kirche Siziliens groBe Beachtung, waren von den Erzbischöfen sowie den direkt Rom unterstellten Bischöfen offenbar besonders begehrt. Die Tatsache, dass etwa dem namentlich nicht bekannten Bischof von Siracusa noch 1188 von Clemens III. der Gebrauch des Palliums untersagt werden musste, obwohl Monreale bereits fünf Jahre zuvor zu dessen neuer Metropole erhoben worden war, verdeutlicht, dass die Kirchenordnung immer noch labil war, so dass vermutlich der Metropolit von Monreale auf jegliche Versuche der Minderung seiner Qualität als Metropolit empfindlich reagierte und nicht zögerte, Rom einzuschalten ${ }^{131}$.

Gerade mit dem vergleichenden Blick auf die Situation in Kalabrien wird die hohe Bedeutung der Pallien für die Kirchen Siziliens deutlich. Mit Reggio Calabria, Cosenza und Santa Severina waren hier immerhin auch drei Erzbistümer vorhanden. Doch lediglich eine am 19. November 1165 von Alexander III. für Erzbischof Roger von Reggio Calabria und eine am 22. März 1184 von Lucius III. für Erzbischof Meleto von Santa Severina ausgestellte Urkunde kommen auf das Pallium zu sprechen ${ }^{132}$. Und auch die Epochengrenze von 1198 ändert an diesem Befund nichts ${ }^{133}$. Übertragungen von Pallien an die dortigen Erzbischöfe sind ebenso wenig bekannt. Damit unterscheidet sich die Situation in Kalabrien von derjenigen auf Sizilien erheblich. Reiner Überlieferungszufall?

Vielleicht ist die hohe Nachfrage nach Pallien auf der Insel Sizilien angesichts der engen Bindung dieser Kirchen an den Herrscher nicht als Ausdruck der Romnähe und die ausgebliebene Nachfrage in Kalabrien als Ausdruck der Romferne zu interpretieren. Dass ein Erzbischof in Rom um sein Pallium nachsuchte ist an und für sich nicht bemerkenswert, sondern entspricht der Norm, die vor allem durch die Kopplung des Rechtes, Bischöfe zu weihen und Synoden abzuhalten, an das Pallium unter Paschalis II. von Rom propa-

129 IP 10 S. 233 Nr. $\star 33$.

130 Gesta Innocentii, ed. Gress-Wright (wie Anm. 13) S. 52 Z. 2; vgl. dazu auch KAMP: Kirche (wie Anm. 10) Bd. 3 S. 1126.

131 Der Nachfolger Richard Palmers ist unbekannt, eventuell war das Bistum vakant, erst mit Laurentius ist ab November 1192 wieder ein Bischof namhaft zu machen, vgl. KamP: Kirche (wie Anm. 10) Bd. 4 S. 1234.

132 IP 10 S. 23 Nr. 20 für Reggio Calabria; IP 10 S. 127 Nr. 2 für Santa Severina (= RI 4/4/4/1 Nr. 1009). Über Meleto weiß man praktisch nichts, vgl. KAMP: Kirche (wie Anm. 10) Bd. 2 S. $882 f$.

133 Wenn die Aussage von PaCAut (wie Anm. 47) S. 55, dass die Päpste sich intensiv darum bemühten, alle Erzbischöfe des Königreichs mit Pallien auszustatten, zutrifft, so fielen ihre Bemühungen in Kalabrien offenbar auf keinen allzu fruchtbaren Boden. 
giert und vermutlich auch rasch in der gesamten Christianitas akzeptiert worden war $^{134}$. Das Auffällige ist folglich nicht der Empfang des Palliums an sich, sondern der Umgang der Zeitgenossen damit beziehungsweise der Niederschlag, den das Pallium und sein Empfang in den zeitgenössischen Quellen fanden. Dieser Befund zeigt die Relevanz der Thematik für die Zeitgenossen $\mathrm{an}^{135}$. Denn die Pallien erweisen sich in dieser Perspektive auf der Insel Sizilien als ein Mittel der Binnendifferenzierung, die nicht nur aufgrund der Neuorganisation der Kirchenstruktur notwendig wurde, sondern ebenso durch die große Nähe zum Herrscher. Das vermeintlich römische Instrument stellt sich gerade im Vergleich mit der Kirche Kalabriens als zwar in deutlicher Verbindung mit Rom stehendes Instrument dar, das seine Wirkungskraft jedoch vorrangig im Kreis der sizilischen Kirche zu entfalten hatte und hier von Bedeutung war ${ }^{136}$. Dass sie in Kalabrien fehlen, ist nicht allein durch den Überlieferungsverlust bei den Palliumurkunden zu erklären, denn auch Nachrichten über den Empfang des Palliums, sei es persönlich in Rom oder durch die Zusendung mit Hilfe eines Legaten oder einer anderen vom Papst beauftragten Person, fehlen für diese Region. Die Ursache dürfte in einer größeren Stabilität der kalabrischen Metropolitanstruktur liegen, die sich seit ihrer Errichtung kaum verändert hatte. Zwar führte die Neugründung und Exemtion des Bistums Miletos zu einer Veränderung, doch diese ist nicht mit den Dimensionen auf Sizilien zu vergleichen. Denn die drei Erzbistümer Cosenza, Reggio Calabria und Santa Severina bestanden während des gesamten Untersuchungszeitraums und bestimmten die kirchliche Struktur Kalabriens ${ }^{137}$. Hin-

134 Die Regelung Paschalis' II. fand auch Aufnahme in den «Liber Extra» vgl. X 1.6.4, ed. FRIEDBERG: CIC, Bd. 2, Sp. 49. Das genannte Verbot findet sich bereits bei Gregor I., erhielt jedoch offenbar erst seit Paschalis II. größere Bedeutung; zur rechtlichen Bedeutung des Palliums vgl. vor allem Rainer MURAuer: Papst, Metropolit, Bischof um 1200. Zur Verzögerung der Weihe des Elekten Heinrich von Straßburg, in: RHM 43 (2001) S. 257-310, hier S. 274-280.

135 Auf die Aussagekraft der Palliumurkunden in diesem Sinne hatte erstmals hingewiesen ZotZ: Pallium (wie Anm. 118); vgl. auch JohrendT: Papsttum (wie Anm. 97) S. 7275 u. 231f.; zum Problem der Überlieferung der Palliumurkunden jüngst ab Beispiel der Reimser Kirche Ludwig FALKENSTEIN: Zu verlorenen päpstlichen Privilegien und Schreiben. Palliumverleihungen an die Erzbischöfe von Reims (8.-12. Jahrhundert), in: Eloquentia copiosus. Festschrift für Max Kerner zum 65. Geburtstag, hg. v. Lotte KÉRY, Aachen 2006, S. 181-224.

136 Ähnliches hatte ZOTZ: Pallium (wie Anm. 118) für die Reichskirche vor allem des 10. Jahrhunderts herausgearbeitet.

137 Einen Sonderfall bildet lediglich das griechische Erzbistum Rossano, dem zumindest am Ende des 12. Jahrhunderts keine Suffragane unterstanden, vgl. KamP: Kirche (wie Anm. 10) Bd. 2 S. 872; zur Entwicklung des Verhältnisses zwischen der griechischen Kirche Unteritaliens und dem Papsttum zwischen dem 11. und 13. Jahrhundert auch den schon etwas älteren Überblick bei Peter HeRDE: Das Papsttum und die griechische Kirche in Süditalien vom 11. bis zum 13. Jahrhundert, in: DA 26 (1970) S. 1-46; Wiederabdr. in: DERS.: Gesammelte Abhandlungen und Aufsätze, Bd. 2/1, Stuttgart 
zu mag noch kommen, dass die Bischöfe Siziliens und hier vor allem die Erzbischöfe stärker als diejenigen Kalabriens auf den Hof ausgerichtet waren, was unter anderem in der Zusammensetzung des Hofes und der Wahrnehmung unterschiedlichster Ämter in der königlichen Zentralverwaltung durch die Bischöfe Siziliens zum Ausdruck kommt, namentlich der Stellung der Bischöfe als Familiaren des Königs ${ }^{138}$. Die Konkurrenz und das Bedürfnis, sich von Mitstreitern in diesem Gremium absetzen zu können, waren hier ungleich höher als unter den kalabrischen Bischöfen. Die Pallien der sizilischen Erzbischöfe könnten auch aus diesem Grund im Gegensatz zu denjenigen ihrer kalabrischen Kollegen in der Überlieferung so tiefe Spuren hinterlassen haben. Ein Element, das aus römischer Perspektive die Bindung zwischen der Ortskirche und der päpstlichen Zentrale stärken sollte, nutzen die Bischöfe der Insel in dieser Perspektive zur Binnendifferenzierung des sizilischen Episkopates, die offenbar aufgrund der dynamischeren Situation vor allem in ihrer zeremoniellen und zeichenhaften Zurschaustellung notwendiger war als in der Terrafer$\mathrm{ma}^{139}$.

Sonstige Nachrichten über Rombesuche sizilischer und kalabrischer Bischöfe sind spärlich - abgesehen von den Nachweisen zum Dritten und Vierten Laterankonzil ${ }^{140}$. Hatte Werner Maleczek erst jüngst herausgearbeitet, dass praktisch alle Bischöfe des Reiches nördlich der Alpen im Pontifikat Innozenz' III. mindestens einmal an der Kurie weilten, so fehlen vergleichbare Studien zu Reichsitalien und dem Königreich Sizilien ${ }^{141}$. Über den Rombesuch des Abtes

2002, S. 1-38; sowie eine überarbeitete Version bei DERS.: The Papacy and the Greek Church in Southern Italy between the eleventh and the thirteenth Century, in: LOUd/MeTCALFE: Society (wie Anm. 39) S. 213-251; allgemein auch André JACOB/ Jean-Marie MARTIN: Die griechische Kirche in Italien (650-1050), in: Die Geschichte des Christentums, Bd. 4: Bischöfe, Mönche und Kaiser 642-1054, hg. v. Gilbert DRAgON/Pierre Riché/André VAucheZ, Freiburg u. a. 1994, S. 366-387; sowie jüngst auch die Muslime einschließend LOUD: Latin Church (wie Anm. 5) S. 494-520.

138 Nach der Reform des Familiarenrates und der Erhöhung der Anzahl der Familiaren auf zehn im Jahr 1168 waren fünf von ihnen Kleriker - dabei spielte der Erzbischof von Palermo, der stets vom König nomminiert wurde, eine herausragende Rolle, vgl. TAKAYAMA: Administration (wie Anm. 87) S. 115-123; DERS.: Familiares Regis and the Royal Inner Council in Twelfth-Century Sicily, in: EHR 104 (1989) S. 357-372, hier S. 361-365; Loud: Latin Church (wie Anm. 5) S. 274f. Zur zentralen Stellung des Familiarenkollegs für Sizilien und Kalabrien vgl. auch die schematische Darstellung bei Houben: Roger II. (wie Anm. 3) S. 161; sowie für die Zeit Wilhelms II. die Ausführungen bei SCHLICHTE: König (wie Anm. 9) S. 310-318.

139 Dort war die Kirchenorganisation in der zweiten Hälfte des 12. Jahrhunderts soweit gefestigt, dass man nicht von einer Erhöhung einfacher Bistümer zum Erzbistum oder Ähnlichem ausging.

140 Siehe dazu unten bei Anm. 197.

141 Werner MALECZEK: Der Mittelpunkt Europas im frühen 13. Jahrhundert. Chronisten, Fürsten und Bischöfe an der Kurie zur Zeit Papst Innocenz' III., in: RHM 49 (2007) S. 89-157, behandelt im Anhang (S. 141-157) zwar auch andere Regionen Europas, doch Italien bleibt ausgespart. 
Bartholomeus von S. Maria del Patir, der dort vor August 1105 von Paschalis II. für das griechische Kloster ein Privileg erwirkte, erfährt man aus der Vita des Abtes $^{142}$. Nach 1198 ist die Reise des Erzbischofs Dionysius von Santa Severina anzuführen, der 1205 nach Rom reiste, um seine Wahl durch den Papst bestätigen zu lassen ${ }^{143}$. Doch dies sind nur einzelne Nachrichten. Gemessen an der vor allem bis in die 1120er Jahre hinein sehr engen personalen Bindung der unteritalienischen Kirche in ihrer Gesamtheit scheint der Austausch durch den Pallienempfang und ad-limina-Besuche zwischen den Kirchen Kalabriens und Sizilien mit Rom gering gewesen zu sein.

\section{Weihen}

Sowohl die Anzahl der Weihen als auch die Anzahl der Urkunden, in denen die Päpste immer wieder festlegten, dass Bischöfe der Insel Sizilien allein von ihnen geweiht werden können, erstaunt. Im Konkordat von Benevent war festgelegt worden, dass der Papst alle Weihen im Königreich Sizilien durchführen dürfe ${ }^{144}$. Die häufige Betonung dieses Weiherechtes in den einzelnen Urkunden demonstriert den Stellenwert, den die Päpste dieser Regelung zuwiesen ${ }^{145}$. Und sie kann nur zum Teil durch die Neuorganisation des Kirche Siziliens erklärt werden, bei der die Zuständigkeiten der Metropoliten gegenüber ihren Suffraganen erst abgegrenzt und eingeübt werden mussten. Denn dies galt ebenso für den kalabrischen Raum, in dem wie auf Sizilien eine lateinische Kirche erst neu geschaffen werden musste. Weihen, die allein durch den Papst oder eine von ihm dazu beauftragte Person vorgenommen werden

142 Vita S. Bartholomaei confessortis III c. 24, ed. AASS Sept. Bd. 8, S. 810-826, hier S. 819, vgl. auch Loud: Latin Church (wie Anm. 5) S. 215.

143 Vgl. Kamp: Kirche (wie Anm. 10) Bd. 2 S. 885.

144 MGH Const. 1, Nr. 413 S. 588-590, hier S. $589 \$$ 6: Consecrationes et visitationes libere Romana ecclesia in omni regno nostro habebit. Die Forschung hat die Formulierung als ein exklusives Weiherecht des Papstes gedeutet, so etwa PACAUT (wie Anm. 47) S. 39; ebenso SCHLICHTE: König (wie Anm. 9) S. 130. Aus der Formulierung libere habere ist meines Erachtens jedoch kein exklusives Weiherecht abzuleiten, das andere von der Weihe ausschließt. Die typische Formulierung für ein exklusives Weiherecht wäre hingegen cuius episcopus non nisi a Romano pontifice consecrationis munus recipere debet, so etwa formuliert von Alexander III. in IP 10 S. 318 Nr. 73, ed. Migne PL 200 Sp. 583586, hier Sp. 583D, für den Bischof Richard von Siracusa.

$145 \mathrm{Zu}$ den Weihen für unteritalienische Bischöfe bis $1100 \mathrm{vgl}$. LOUD: Latin Church (wie Anm. 5) S. 208-212, der jedoch dafür eintritt, die Weihen vorrangig in ihrem religiösen Kontext zu betrachten, in dem es den Päpsten möglich war, sich als guter Hirte darzustellen. Zur Bedeutung der Weihen vgl. jedoch Rober L. BENSON: The Bishopelect. A Study in Medieval Ecclesiastical Office, Princeton N. J. 1968, S. 96f., sowie die Bemerkungen bei JOHRENDT: Sonderfall (wie Anm. 2) S. 252f.; SCHRÖR: Metropolitangewalt (wie Anm. 119) S. 191-198, und die Bemerkungen von DERS. in diesem Band. 
konnten, sind in Kalabrien für Bischöfe und Äbte bekannt. Doch vermutlich kamen die Äbte und Bischöfe nur in drei Fällen nach Rom - ansonsten scheinen die Weihen bei den Kalabrienreisen der Päpste durchgeführt worden zu $\operatorname{sein}^{146}$.

Dies war auf Sizilien nicht möglich, da der Papst nie nach Sizilien gereist war. Die Italia Pontificia verzeichnet 20 Nummern, die sich auf Weihen oder Weiheregelungen beziehen. Lediglich ein einziges Mal beziehen sich die Regelungen auf die Abtsweihe. Cölestin III. bestätigte dem Elekten Berard von Messina am 13. November 1196, dass die Äbte der griechischen Klöster ihre Weihen vom Erzbischof von Messina zu empfangen hätten ${ }^{147}$. Auch darin unterscheidet sich die Situation auf Sizilien deutlich von der kalabresischen, wo sich Äbte auch in Form einer Fälschung um eine Weihe durch den Papst bemühten - vermutlich um eine größere Eigenständigkeit gegenüber dem Suffraganbischof zu erhalten ${ }^{148}$. Die Klöster Siziliens scheinen sich nicht im selben Maße wie diejenigen Kalabriens um eine Anbindung an die Römische Kirche bemüht zu haben. Sie traten nicht von sich aus an Rom heran, um durch eine verstärkte Rombindung eine größere Unabhängigkeit von ihrem Diözesanbischof zu erhalten. Dieses mangelnde Bedürfnis, sich durch eine Weihe in Rom abzusichern, ist in den Urkunden auch für die Bischöfe festzustellen. Lediglich im Falle von Catania schrieb Urban II. 1092 fest, dass der Bischof durch den Papst zu weihen sei ${ }^{149}$. Dieser Befund erstaunt um so mehr, als Alexander III. 1166 in einem Schreiben an König Wilhelm II. von Sizilien anmahnte, dass alle Elekten, die durch den Papst zu weihen seien, auch nach Rom reisten, um dort ihre Weihe zu empfangen ${ }^{150}$. Allein in den Privilegien für die einzelnen Bistümer findet sich diese Regelung nicht - der Anspruch Alexanders III. scheint daher wohl eher ein allgemeiner gewesen zu sein, als dass er sich auf konkrete Privilegien stïtzte. Auch die konkrete Umsetzung der Weihe des nächsten Palermitaner Erzbischofs belegt, dass die Weihe dieses Metropoliten durch Rom zwar ein Anspruch des Papstes war, dem man auf der Insel jedoch nicht nachkam, was schließlich auch Alexander III. einsehen musste und die Weihe Walters von Palermo am 22. Juni 1169 durch die Suffragane des Erzbischofs genehmigte. Dem Kardinalpresbyter Johannes von S. Anastasia, sollte bei der Weihe keine tragende Rolle zukommen ${ }^{151}$.

Obwohl diese Beschwerde Alexanders III. deutlich darauf hinweist, dass nicht alle Elekten der von ihm eingeforderten Pflicht nachkamen, so lassen sich doch einige Beispiele zusammentragen, dass sizilische Bischöfe zum Papst reis-

\footnotetext{
146 JOHRENDT: Sonderfall (wie Anm. 2) S. $256 f$.

147 IP 10 S. 342 Nr. 31 bzw. S. 348 Nr. 1.

148 Vgl. JOHRENDT: Sonderfall (wie Anm. 2) S. $254 \mathrm{f}$.

149 IP 10 S. 290 Nr. 19.

150 IP 8 S. 51 Nr. *196. Der Brief ist bei Hugo Falcandus überliefert, zur Sache vgl.

JOHRENDT: Sonderfall (wie Anm. 2) S. 253f.

151 IP 10 S. 232 Nr. 32 mit den Nebenregesten S. 265 Nr. 12 und S. 271 Nr. 7.
} 
ten, um dort ihre Weihe zu empfangen. So weihte Urban II. Gerlandus von Agrigento $^{152}$ und Ansger von Catania ${ }^{153}$, Alexander III. Johannes von Catania ${ }^{154}$ und Lucius III. Wilhelm von Monreale ${ }^{155}$. Möglicherweise weihte Gregor VII. Bischof Robert von Troina/Messina, sollte dieser tatsächlich nach Rom gereist $\operatorname{sein}^{156}$ und bereits Leo IX. hatte Humbert von Silva Candida zum Erzbischof von Sizilien geweiht ${ }^{157}$, ohne dass dieser jedoch jemals nach Sizilien kam. Abgesehen von Johannes von Catania und Wilhelm von Monreale, erfolgten die Weihen somit bevor Urban II. 1098 Roger I. das Legationsprivileg ausstellte.

Alle anderen Weiheregelungen in päpstlichen Privilegien für sizilische Empfänger betreffen die Weihekompetenz der sizilischen Bischöfe. Dies ist zu weiten Teilen durch die Neuorganisation der sizilischen Kirche zu verstehen, jedoch nicht nur. Dies gilt zunächst für die Regelung Anaklets II. vom 27. September 1130, dass der Bischof von Palermo die Weihegewalt über die Bischöfe von Siracusa, Agrigento, Mazara del Vallo und Catania besitze, mithin über seine Suffragane ${ }^{158}$. Das war nichts ungewöhnliches, zumal die Weihegewalt über seine Suffragane dem Metropoliten kirchenrechtlich zustand ${ }^{159}$. Ähnlich handelte Anaklet II., als er am 14. September 1131 Cefalù zum Bistum erhob und die Weihe des Bischofs von Cefalù dem zuständigen Metropoliten in Messina übertrug ${ }^{160}$. Auch dies entsprach den normalen Gepflogenheiten. Bei Catania erstaunt dieser Schritt lediglich, da Urban II. 1092 festgelegt hatte, dass die Bischöfe Catanias allein durch den Papst geweiht werden sollten. Das Privileg Anaklets II. ist insofern zwar als eine „Normalisierung“ der Situation auf Sizilien zu werten, indem er die Sonderstellung Catanias aufhob und dieses wie andere Suffraganbistümer in anderen Kirchenprovinzen in der üblichen Weise an den Metropoliten band. Bemerkenswert bleibt jedoch ein Reflex auf diese Normalisierung unter Alexander III. Denn Alexander knüpfte bewusst an die Politik Urbans II. wieder an, den er in dem dazugehörigen Privileg auch

152 IP 10 S. 264 Nr. $\star 8$.

153 IP 10 S. $290 \mathrm{Nr}, \star 18$.

154 IP 10 S. 291 Nr. ${ }^{\star} 24$.

155 IP 10 S. 276 Nr. *6 (= RI 4/4/4/1 Nr. 474). Die Weihe Wilhelms vollzog Lucius III. in Velletri.

156 IP 10 S. 337 Nr. 17. Gregor VII. spricht jedoch lediglich davon, dass er Robert weihen werde, wenn dieser nach Rom komme. Von der Weihe geht aus BECKER: Graf (wie Anm. 1) S. 142 u. 172. Das entsprechende Schreiben Gregors VII. ist JL 5233, ed. Greg. VII. Reg. IX/25 hier S. 608 Z. 20-25.

157 IP 10 S. 186 Nr. $\star 73$. Siehe auch unten Anm. 177.

158 IP 8 S. 37 Nr. 137, sowie die Nebenregesten in IP 10 S. 252 Nr. 3, S. 264 Nr. 10 , S. 291 Nr. 21 u. S. 318 Nr. 72.

159 Vgl. jüngst zusammenfassend SCHRÖR: Metropolitangewalt (wie Anm. 119) S. 17.

160 IP 10 S. 364 Nr. 1. 
explizit nannte ${ }^{161}$, weihte Bischof Johannes von Catania persönlich und schrieb fest, dass auch dessen Nachfolger durch den Papst zu weihen seien ${ }^{162}$. Die Umstrukturierung der sizilischen Kirche durch die Erhebung Monreales zum Erzbistum machte die Frage der Unterordnung und Weihe durch den Palermitaner Hirten jedoch obsolet. Zusammen mit der gescheiterten engeren Anbindung des Palermitaner Erzbischofs ist unter Alexander III. damit ein verstärktes Bemühen zu fassen, die sizilische Kirche durch das Instrument der Weihen wieder stärker an Rom zu binden. Doch dieses Angebot stieß in der sizilischen Kirche offenbar auf wenig Gegenliebe, man war an einer engeren Bindung an Rom offenbar nicht interessiert.

\section{Prosopographischer Austausch mit Rom}

Den Rahmen für den prosopographischen Austausch auf der Ebene der Bischöfe zwischen Rom und den Regionen Sizilien und Kalabrien gab die dominierende Stellung der normannischen Herrscher in ihrer Kirche vor ${ }^{163}$. Für die über 140 Bischöfe, die das Regno am Ende des 12. Jahrhunderts hatte, war der König nicht nur der entscheidende Bezugspunkt, bis 1198 war es zudem kaum vorstellbar, dass ein Kandidat gegen den Willen des Herrschers erhoben wurde ${ }^{164}$. Selbst Innozenz III. hatte Kaiserin Konstanze und Friedrich II. ein Zustimmungsrecht zur Wahl zugestanden ${ }^{165}$. Da die Quellen für die Ebene

161 Migne PL 200 Sp. 495-497 Nr. 495, hier Sp. 496A; Quapropter piae recordationis Urbanus papa ...

162 Zur Weihe IP 10 S. 291 Nr. *24; dass der Bischof von Catania allein vom Papst geweiht werden dürfe, schrieb Alexander III. 1168 und erneut 1171 fest, IP 10 S. 292 Nr. 25 u. 26.

163 Zum Episkopat des Königreichs Sizilien vgl. neben der Studie von KaMP: Kirche (wie Anm. 10), die den Episkopat ab der staufischen Zeit erfasst und prosopographisch mustergültig aufgearbeitet hat, für das 12. Jahrhundert DERS.: Episkopat (wie Anm. 25); DERS.: Herkunft (wie Anm. 79); vgl. PACAUT (wie Anm. 47).

164 Vgl. dazu DeÉR: Papsttum (wie Anm. 1) S. 258f.; KAMP: Episkopat (wie Anm. 25) S. 126-129; ENZENSBERGeR: Wilhelm (wie Anm. 8) S. 401-409; LOUD: Control (wie Anm. 12) S. 154f. mit dem illustrativen Beispiel der Erhebung in Valva; SCHLiCHTE: König (wie Anm. 9) S. 128-131; die enge Bindung vor allem zwischen dem im Süden des Regno zu verortenden Episkopat und der sizilischen Krone betonte auch DIES.: Chiesa e feudalesimo, in: Nascita di un regno. Poteri signorili, istituzioni feudali e strutture sociali nel Mezzogiorno normanno (1130-1194): Atti delle diciasetttesime giornate normanno-sveve (Bari, 10-13 ottobre 2006), hg. v. Raffaele LiCiNIO/ Francesco Violante, Bari 2008 (Centro di studi normanno-svevi, Università degli Studi di Bari. Atti 17), S. 143-176, hier S. 160-162.

165 Vgl. Reg. Inn. III., I/411 sowie das Parallelschreiben I/412 an alle Prälaten des Königreichs Sizilien. 
unter den Bischöfen vor allem für die Zeit vor 1198 spärlich fließen, werde ich mich im Folgenden allein auf die Bischöfe konzentrieren ${ }^{166}$.

Die Normannenherrscher beeinflussten die Zusammensetzung des Episkopates jedoch nicht nur durch die Kontrolle der Wahlen, sondern auch durch ihre für die Bistümer entscheidende wirtschaftliche Rolle, die bis zum Ende der Hauteville und darüber hinaus bestand ${ }^{167}$. Dieser maßgebliche Einfluss auf die Besetzung der Bistümer war auch Friedrich II. - zumindest am Beispiel von Palermo fassbar - nicht bereit aufzugeben ${ }^{168}$. Und dem faktischen Einfluss des Königs konnten (oder wollten?) die Päpste offenbar nicht allzu viel entgegensetzen - auf der Insel Sizilien waren ihnen bis 1198 durch die apostolische Legation der Könige die Hände gebunden und in Kalabrien scheint es keine größeren Bemühungen der Kurie um eine verstärkte Kontrolle bei der Bischofserhebung gegeben zu haben. Dieser Befund unterscheidet sich erstaunlicherweise vom Rest des Königreiches, in dem zumindest für die Regierungszeit Wilhelms II. (1166-1189) ein von Pacaut als „systematisch“ bezeichnetes Bemühen Roms um eine Kontrolle der Wahlen zu fassen ist, da die Wahlen nun durch Rom überprüft und die Bischöfe dann bestätigt wurden ${ }^{169}$. Von der Eignung der Kandidaten her scheinen die Päpste offenbar auch wenig Handlungsbedarf gesehen zu haben, da die normannischen Könige offenbar keine ungeeigneten Personen auf Bischofsstühle hievten ${ }^{170}$. Zwar ist spätestens mit Wilhelm II. eine Abnahme solcher Bischöfe festzustellen, die Regionen außer-

166 So erwies sich durch jüngste Forschungen auch die päpstliche Kapelle als ein wichtiges personelles Bindeglied zwischen den Regionen und dem römischen Zentrum. Doch abgesehen von der Dissertation von Reinhard ElZE: Die päpstliche Kapelle im 12. und 13. Jahrhundert, in: ZRGKanAbt 36 (1950) S. 145-204; Wiederabdruck in: Päpste Kaiser - Könige und die mittelalterliche Herrschaftssymbolik. Ausgewählte Aufsätze, hg. v. Bernhard Schimmelpfennig/Ludwig SCHMUgGe, Collected Studies Series CS 152, London 1982, Nr. II S. 145-204, fehlen neuere und vor allem prosopographisch ausgerichtete Studien zur päpstlichen Kapelle, die diese Dimensionen erst erschließen. Wie fruchtbar auch regionenbezogene Studien für die päpstliche Kapelle sein können belegte jüngst Maria Pia AlBerzoni: Gli interventi della Chiesa di Roma nella provincia ecclesiastica milanese, in: Herbers/JOHRENDT: Papsttum (wie Anm. 16) S. 135-181. Unter den Kaplänen der normannischen Könige sind päpstliche Kapläne offenbar fast ausschließlich in der Zeit Friedrichs II. nachzuweisen, vgl. dazu demnächst die Dissertation zur normannisch-staufischen Hofkapelle im Königreich Sizilien (1130-1266) von Lioba Geis (Aachen), der ich für diese Auskunft herzlich danke.

$167 \mathrm{Vgl}$. SCHLichte: König (wie Anm. 9), zusammenfassend S. 126. Zu den wirtschaftlichen Zuwendungen der Könige an die Bistümer vgl. jüngst die knappe Zusammenfassung bei Decimae. Il sostegno economico dei sovrani alla Chiesa del Mezzogiono nel XIII secolo dai lasciti di Eduard Sthamer e Norbert Kamp, hg. v. Kristjan TOOMASPOEG, Rom 2009 (Ricerche dell'Istituto storico germanico di Roma 4), S. 39-52.

168 Siehe oben bei Anm. 10.

169 Pacaut (wie Anm. 47) S. 57. Kritisch zur Sichtweise Pacauts, der stets von einem Antagonismus zwischen Papsttum und sizilischem Königtum ausgeht LOUD: Papacy (wie Anm. 39) S. 179f., sowie SCHLichte: König (wie Anm. 9) S. $128 \mathrm{f}$.

170 Dies betont Loud: Control (wie Anm. 12) S. 153 f. 
halb des Regno entstammten ${ }^{171}$, doch lediglich auf Sizilien ist - wohl aufgrund der engen Verschränkung von Hof und dortigen Bistümern - ein klares Interesse der Herrscher zu erkennen, Personen aus dem eigenen Umfeld zu dortigen Bischöfen zu machen ${ }^{172}$.

Generell ist zu bemerken, dass je nach Bistum für den Untersuchungszeitraum zwischen 30 und 70 Prozent der Bischöfe überhaupt namentlich bekannt sind $^{173}$, so dass die folgenden Aussagen nicht mehr als grobe Linien aufzeigen können. Vorab ist in jedem Fall zu bemerken, das zumindest bis zum Bruch zwischen Roger II. und Calixt II. die Einsetzung eines dem Papst genehmen Bischofs - etwa in einem exemten Bistum - nicht bedeutet, dass dies nicht auch auf den Willen des Hauteville zurückgehen könnte ${ }^{174}$. Denn bis zum Bruch gab es offenbar wenig Kritik an den von Roger betriebenen Bischofserhebungen. Vor allem wenn man ganz Unteritalien betrachtet, gab es bis zu Calixt II. einen deutlichen personellen Austausch zwischen Unteritalien und der Kurie. Denn nicht nur, dass etliche der Kardinäle aus Unteritalien stammten, sondern ebenso wurden auch etliche Kardinäle zu Bischöfen in Unteritalien erhoben ${ }^{175}$. Doch differenziert man den Begriff Unteritalien näher, so wird deutlich, dass dieser Austausch sich nicht auf alle Territorien bezog, die ab 1130 unter einer Königskrone vereint waren. Besonders Montecassino spielt hier eine herausragende und auch eigenständige Rolle, die nicht ohne weiteres mit derjenigen Roms gleichgesetzt werden $\mathrm{kann}^{176}$. Zunächst war vor allem

171 Vgl. Kamp: Herkunft (wie Anm. 79) S. 109; Schlichte: König (wie Anm. 9) zusammenfassend S. 126. Noch bis 1130 war nur ein Bruchteil der Bischöfe Unteritaliens „,normannischer" Herkunft. Etliche Bischöfe kamen vielmehr aus Oberitalien und Deutschland, Vgl. Graham A. LOUD: Church and Churchmen in an Age of Conquest: Southern Italy 1030-1130, in: The Haskins Society Journal 4 (1992) S. 37-53; Wiederabdr. in: DERS.: Conquerors and Churchman in Norman Italy (Variourm Collected Studies Series), Aldershot 1999, VIII S. 37-53, hier S. 44f.

172 Loud: Control (wie Anm. 12) S. 157.

$173 \mathrm{Vgl}$. dazu für den gesamten unteritalienischen Episkopat KAMP: Herkunft (wie Anm. 79) S. 90.

174 So geht LouD: Churches (wie Anm. 171) S. 45, davon aus, dass die Bischöfe der exemten Bistümer - für Kalabrien und Sizilien wären dies Bisignano, Mileto, San Marco Argentano und Cefalù - durch den Papst bestimmt wurden.

175 Vgl. Loud: Latin Church (wie Anm. 5) S. 218, der vor allem den Austausch mit Montecassino hervorhebt. Doch dies ist wohl weniger auf eine allgemeinen Austausch mit Unteritalien zurückzuführen, sondern auf die engen Bindungen der Päpste in der frühen Zeit der Reform zu diesem Kloster. Für den personellen Austauch zwischen Rom und den unteritalienischen Kirchen im 12. Jahrhundert grundlegend ist immer noch KAMP: Herkunft (wie Anm. 79).

176 Zur Rolle Montecassinos und Roms für Unteritalien vgl. Herbert Edward John COWDREY: The age of abbot Desiderius. Montecassino, the Papacy and the Normans in the 11th and early 12th centuries, Oxford 1983, bes. S. 107-176. Auf die engen Austauschprozesse zwischen Montecassino und Rom hat in Hinblick auf die Formulierung von Papsturkunden zuletzt Florian HARTMANN: Das Enchiridion de prosis et rithmis Alberichs von Montecassino und die Flores rhetorici, in: QFIAB 89 (2009) S. 1-30, 
die monastische Tradition war für den Episkopat Unteritaliens prägend, der sich erst im Laufe des 12. Jahrhundert von diesen Wurzeln entfernte.

Und zeitgleich waren auch die personalen Bindungen zwischen Rom und Sizilien sowie Kalabrien eng. Leo IX. und Urban II. erhoben immerhin Personen aus ihrem engsten Umkreis zu Erzbischöfen in diesen Regionen. Leo IX. ernannte Humbert von Silva Candida, der damals noch nicht Kardinal war, zum Erzbischof von Sizilien - ohne dass dieser jedoch die Insel jemals betreten hätte ${ }^{177}$. Doch die Erhebung zeigt, welche Bedeutung Leo IX. den unteritalienischen Verhältnissen beimaß, da er im Jahre 1050 noch nicht über größere Personalressourcen verfügte, die er nach Belieben einsetzen konnte ${ }^{178}$. Der erste Kardinal, der als Kardinal zu einem Erzbischof in den beiden Untersuchungsregionen erhoben wurde, war Rangerius, Kardinalpriester von S. Susa, der 1089/1090 von Urban II. zum Erzbischof von Reggio Calabria ernannt wurde, ${ }^{179}$ auch wenn Urban dafür ursprünglich offenbar seinen ehemaligen Lehrer, den Karthäuser Bruno von Köln, vorgesehen hatte, der jedoch verzichtete und statt dessen die Kartause S. Maria di Turri in Kalabrien gründe$\mathrm{te}^{180}$.

Hatte Humbert sein anvisiertes Wirkungsfeld Sizilien nie betreten, so gab Rangerius in Reggio Calabria offenbar nur ein kurzes Gastspiel, denn bereits im März 1095 ist in Reggio Rudolf als neuer Erzbischof zu belegen. Rangeri-

aufmerksam gemacht, nach dessen Studien man Albert von Montecassino für die Entwicklung der päpstlichen Kanzlei sicherlich ein größere Bedeutung wird zuschreiben müssen.

177 IP 10 S. 186 Nr. ^73; zu Humbert vgl. auch Rudolf HüLs: Kardinäle, Klerus und Kirchen Roms: 1049-1130, Tübingen 1977 (Bibliothek des Deutschen Historischen Instituts in Rom 48), S. 131-134. Humbert unterzeichnet eine Urkunde vom 2. Mai 1050 als Humbertus Siciliensis archiepiscopus, ed. Die Konzilien Deutschlands und Reichsitaliens 1023-1059, hg. v. Detlev JASPER, Hannover 2010 (MGH Conc. 8), Nr. 30 S. 288 Z. 11. Zur Sache vgl. auch BECKER: Graf (wie Anm. 1) S. 131 u. 160. Zur Wertung der Erhebung vgl. auch BAYER (wie Anm. 117) S. 57.

178 Erst unter Alexander II. ist die Personaldecke der Reformer etwas größer geworden, vgl. dazu die Bemerkungen bei Tilmann SCHMIDT: Alexander II. und die römische Reformgruppe seiner Zeit, Stuttgart 1977 (Päpste und Papsttum 11), S. 153.

179 HÜLS (wie Anm. 177) S. 207-209 Nr. 2, hier S. 208, geht von der Erhebung Rangerius' auf der Synode in Melfi im September 1089 aus, während Alfons BECKER: Papst Urban II. (1088-1099), Stuttgart 1964-1988 (MGH Schr. 19), hier Bd. 2 S. 96f., von frühestens 1090 spricht. Er wertet die Erhebung Rangerius' als bewussten Akt der „Romanisierung“ Unteritaliens und seiner Kirchen durch Rom. Zu ihm vgl. auch Klaus GANZER: Die Entwicklung des auswärtigen Kardinalats im hohen Mittelalter. Ein Beitrag zur Geschichte des Kardinalskollegiums vom 11. bis 13. Jahrhundert, Tübingen 1963 (Bibliothek des Deutschen Historischen Instituts in Rom 26), S. 45-49; vgl. allgemein auch LOUD: Latin Church (wie Anm. 5) S. 216; DERS.: Churches (wie Anm. 171) S. 44; BECKER: Graf (wie Anm. 1) S. 167.

$180 \mathrm{Vgl}$. BeCKeR: Urban II. (wie Anm. 179) S. 96. Zu Brunos Wirken in Kalabrien vgl. jetzt zusammenfassend BECKER: Graf (wie Anm. 1) S. 202-206. Die engen Beziehungen zu Urban II. blieben offenbar bis zum Tod Urbans II. bestehen. 
us kehrte daher Ende 1094/Anfang 1095 an die Kurie zurück, wo er als Kardinal bis zum Juli 1096 tätig war. Dauerhaft nahm hingegen Arnulf von Cosenza (1059-80) seine Tätigkeit als Erzbischof war. Er stand in engem Kontakt zu den Reformern in Rom ${ }^{181}$. Doch nach der Jahrhundertwende scheint es keinen weiteren personellen Austausch zwischen Rom und den Kirchen Siziliens und Kalabriens gegeben zu haben. Die so genannte Sizilische Partei im Kardinalskollegium rekrutierte sich - anders als der Name es vermuten lässt - zumindest nicht aus Klerikern, die mit kalabrischen oder sizilischen Kirchen in enger Verbindung stehen ${ }^{182}$. Römischer Herkunft scheint der nur 1194 belegte Bischof von Cefalù, Benedictus Romanus, zu sein, doch über seinen Werdegang zuvor, seine Beziehungen zum päpstlichen Umfeld oder ähnliches ist nichts bekannt ${ }^{183}$.

Kalabrien und Sizilien nehmen damit beim personellen Austausch mit Rom innerhalb des Königreichs Sizilien eine gewisse Sonderrolle ein. Denn auf ganz Unteritalien bezogen war der personelle Austausch zwischen der Kurie und den dortigen Kirchen verhältnismäßig eng. Man kann dort unter Urban II., Paschalis II. und Calixt II. sogar ein Instrument der Anbindung erkennen, das in der zweiten Hälfte des 12. Jahrhunderts in Oberitalien verstärkt eingesetzt wurde: Der Einsatz von Kardinälen, die fest an Ortskirchen gebunden waren ${ }^{184}$. Doch unabhängig davon, wie man diese Massierung von Kardinälen in der unteritalienischen Kirche werten möchte, ob als bewusst von Rom eingesetztes Instrument oder als eher aus den Regionen heraus gesteuert - die Einsetzung der Kardinäle führte ohne Frage zu einer engeren Anbindung an den Papst. Und erstaunlicher Weise bleiben die Kirchen Siziliens und Kalabriens von dieser neuen Qualität der Bindung unberührt, der Versuch das Modell auch nach Reggio Calabria zu übertragen scheiterte.

\section{Päpstliche Kanonisationen}

So weit ich sehe liegen für den Untersuchungszeitraum keine Kanonisationen vor, die Sizilien direkt betreffen. Es ist erstaunlich, dass die Päpste hier ein Mittel zur Bindung der Ortskirchen an Rom nicht nutzten. Denn etliche der Bischöfe aus der Phase des ausgehenden 11. und beginnenden 12. Jahrhunderts

181 KAMP: Herkunft (wie Anm. 79) S. 95.

182 So betont Loud zwar immer wieder, dass es keine Unterbrechung der kirchlichen Kontakte zwischen Rom und Unteritalien durch die Erhebung Siziliens zum Königreich im Jahre 1130 gab, so etwa LOUD: Latin Church (wie Anm. 5) S. 231f; doch auch unter den nach 1159 im Kardinalskollegium anzutreffenden Unteritalienern, ebd. S. 240f., sind keine Personen aus Kalabrien oder Sizilien zu fassen.

$183 \mathrm{Zu}$ ihm vgl. KaMP: Kirche (wie Anm. 10) Bd. 3 S. $1048 f$.

184 Bei der Wertung, dass es sich bei der Erhebung von Kardinälen zu Erzbischöfen und Bischöfen in der unteritalienischen Kirche um eine gezielte Politik der Päpste handelt, meldet Loud: Latin Church (wie Anm. 5) S. 216f., Zweifel an. 
wurden in der weiteren Entwicklung ihrer Bistümer zu einem entscheidenden Bezugspunkt der Diözese ${ }^{185}$. So auch der wohl 1104/5 verstorbene Bischof Gerland von Agrigent, den Urban II. persönlich geweiht hatte und der zum Patron der Agrigenter Kathedrale wurde ${ }^{186}$. Doch die päpstlichen Kanonisationen spielten bei der Verehrung dieser Bischöfe keine größere Rolle. Für den unteritalienischen Bereich ist hier lediglich Gerhard von Potenza anzuführen, der noch 1121 in der Umgebung Calixts II. in Catanzaro nachzuweisen ist und bereits 1123/24 auf Bitten des Bischofs Manfred von Potenza durch Calixt II. heilig gesprochen wurde ${ }^{187}$. Ein 1252 unternommener Versuch, den 1072 verstorbenen Bischof Rainerius von Forcone (das 1256 in L'Aquila aufging) durch den Papst heilig sprechen zu lassen, scheiterte ${ }^{188}$. In der Regel scheint die Verehrung der als heilig geltenden Bischöfe lokal vollzogen worden zu sein, ohne dass der Befund chronologisch jeweils genau aufgearbeitet ist ${ }^{189}$. Abgesehen vom genannten Fall des Gerhard von Potenza ist kein päpstliches Eingreifen festzustellen.

\section{Päpstliche Synoden}

Auf der Insel Sizilien gab es im Untersuchungszeitraum keine päpstliche Synode - anders als in Kalabrien, wo Calixt II. in Crotone eine Synode abgehalten

185 Eine systematische Untersuchung zu den Patrozinien in Unteritalien fehlt, soweit ich sehe. Doch scheint es keine größere Verbreitung von römischen Patrozinien gegeben zu haben. Ein herausragendes Beispiel für die Präsenz der Päpste durch ein Patrozinium ist ohne Frage das in den Abruzzen gelegene Kloster S. Clemente a Casauria, dessen Klostergeschichte als eine „Fortschreibung der Heiligenvita“ interpretiert wurde von Markus SPÄTH: Verflechtung von Erinnerung. Bildproduktion uns Geschichtsschreibung im Kloster San Clemente a Casauria während des 12. Jahrhunderts, Berlin 2007 (Orbis medievalis. Vorstellungswelten des Mittelalters 8), so das Kapitel S. 220 226. Durch die Aktualisierung der Clemensbezüge im 12. Jahrhundert blieb vermittels der Papstreliquien auch Rom in deutlicher Weise in dieser Abtei präsent.

186 Vgl. Kamp: Herkunft (wie Anm. 79) S. 102f. Zur Weihe siehe oben bei Anm. 152.

187 IP 9 S. 484 Nr. ${ }^{\star}$, vgl. dazu auch Ottfried KRAFFT: Papsturkunde und Heiligsprechung. Die päpstlichen Kanonisationen vom Mittelalter bis zur Reformation. Ein Handbuch, Köln u. a. 2005 (ADipl Beih. 9), S. 73f. Zum Aufenthalt in Catanzaro vgl. Beate SCHILlING: Guido von Vienne - Papst Calixt II., Hannover 1998 (MGH Schr. 45), S. 712.

188 Vgl. Krafft (wie Anm. 187) S. 266; Kamp: Kirche (wie Anm. 10) Bd. 1 S. 22. Dass man in diesem Fall die Heiligsprechung durch den Papst forcierte, dürfte nicht zuletzt daran gelegen haben, dass Bischof Thomas von Focrone, der bei Honorius III. die Heiligsprechung betrieb, der päpstlichen Kapelle entstammte und damit der unmittelbaren päpstlichen Umgebung.

189 So ist die Datierung der bei Kamp: Herkunft (wie Anm. 79) S. 103 Anm. 49 genannt sieben und bis auf eine Vita sämtlich in der BHL verzeichneten Viten nicht klar. 
hatte ${ }^{190}$. Wie die Resonanz der Einladungen bei den Bischöfen Siziliens und Kalabriens ausfiel ist schwer einzuschätzen, da die Quellenlage dürftig ist ${ }^{191}$. Der erste Besuch eines Bischofs aus Kalabrien und Sizilien auf einer päpstlichen Synode während des Untersuchungszeitraums ist der Besuch von Erzbischof Arnulf von Cosenza auf der Lateransynode des Jahres $1059^{192}$. Doch immerhin lassen sich auf dem Laterankonzil Paschalis' II im März 1112 die Erzbischöfe Johannes von Reggio Calabria, S. Severina - und der griechische Erzbischof von Rossano, sowie Bischof Wilhelm von Siracusa nachweisen ${ }^{193} .1118$ in Gaeta war hingegen allein der Erzbischof von S. Severina anwesend ${ }^{194}$. So schwierig es daher einzuschätzen ist, wie viele unteritalienische Bischöfe etwa nach dem Bruch zwischen Roger II. und Calixt II. auf dem Zweiten Laterankonzil waren, so wird man doch davon ausgehen können, dass der Hauteville einem avisierten Konzilsbesuch der Bischöfe seines Herrschaftsbereiches nicht besonders aufgeschlossen gewesen sein wird ${ }^{195}$. Zum Dritten Laterankonzil erschienen nicht weniger als 300 Bischöfe ${ }^{196}$. Das Konzil hatte vor allem nach dem Frieden von Venedig, an dem der sizilische König als Vertragspartei Anteil hatte, die Aufgabe, nach der Zeit des Alexandrinischen Schismas die Einheit der Kirche wieder auf eine breite Basis zu stellen, die Wiederholung eines Schismas so weit möglich durch die Regelung «licet de vitanda» zu vermeiden. Dazu waren aus Unteritalien immerhin 72 oder 73 unteritalienischen Bischöfe

190 SCHILling (wie Anm. 187), S. 491-497; Georg GRESSER: Die Synoden und Konzilien in der Zeit des Reformpapsttums in Deutschland und Italien von Leo IX. bis Calixt II. 1049-1123, Paderborn u. a. 2006 (Konziliengeschichte, Reihe A: Darstellungen), S. 470.

191 Zur Situation in ganz Unteritalien bis zum Ende des 11. Jahrhunderts vgl. LouD: Latin Church (wie Anm. 5) S. 205-208, der in gesteigerten Besuchszahlen einen Ausdruck für den gewachsenen päpstlichen Einfluss in Unteritalien sieht. Unergiebig sind die Ausführungen von GRESSER (wie Anm. 190) S. 515-522, der undifferenziert von „Italienern" spricht.

192 Belegt ist sein Aufenthalt durch die Unterschrift unter dem dort verabschiedeten Papstwahldekret, Detlev JASPER: Das Papstwahldekret von 1059. Überlieferung und Textgestalt, Sigmaringen 1986 (Beiträge zur Geschichte und Quellenkunde des Mittelalters 12), S. 117 Z. 304.

193 MGH Const. 1 Nr. 399 S. 570-573, hier S. 573; vgl. dazu LOUD: Latin Church (wie Anm. 5) S. 205.

194 Le Liber pontificalis. Texte, introduction et commentaire par l'abbé Louis DUCHESNE, Bd. 2, Paris 1892 (Bibliothéque des Écoles françaises d'Athénes et de Rome 3/2) S. 315.

195 Auch auf dem Konzil Innozenz' II. von 1135 in Pisa lassen sich keine Bischöfe aus Kalabrien und Sizilien nachweisen, MGH Const. 1 Nr. 402.

196 Zur Zahl vgl. Georgine TANGL: Die Teilnehmer an den allgemeinen Konzilien des Mittelalters, Weimar 1922, S. 212; Raymonde FOREVILLE: Lateran I-IV, Mainz 1970 (Geschichte der ökumenischen Konzilien 6), S. 176 mit Bezug auf die Angaben bei Wilhelm von Tyrus und der Chronik von Montecassino. Zum Dritten Laterankonzil jüngst der knappe Überblick bei Anne J. DugGan: Conciliar Law 1123-1215. The Legislation of the Four Lateran Concils, in: HaRtmann/PENNINGTON: History (wie Anm. 78) S. 318-366, hier S. 333-341. 
erschienen ${ }^{197}$, so dass sie fast ein Viertel des versammelten Episkopats stellten. Unter diesen unteritalienischen Bischöfen stammen wiederum zehn aus Sizilien und Kalabrien. Von den fünf damaligen Erzbischöfen fehlten die Erzbischöfe von Palermo und von Santa Severina, während Messina, Reggio Calabria und Cosenza vertreten waren ${ }^{198}$. Auffallend ist allein, dass sich aus der Reihe der sizilischen Bischöfe neben dem Erzbischof von Messina allein noch Bischof Guido von Cefalù auf den Weg nach Rom gemacht hatte. Das ist deshalb bemerkenswert, da Cefalù zu diesem Zeitpunkt ein exemtes Bistum war und direkt Rom unterstand ${ }^{199}$. Das gilt auch für Bischof Anselm von Mileto, doch reisten aus Kalabrien noch vier weitere Bischöfe nach Rom, so dass die Reise dieses eximierten Bischofs nicht so auffällig ist ${ }^{200}$. Insgesamt wird man damit eher eine Zurückhaltung der sizilischen Bischöfe konstatieren dürfen - vor allem im Vergleich zum Vierten Laterankonzil. Denn 1215 blieb die Insel nicht länger außen vor ${ }^{201}$. Von den wohl 17 Bischöfen aus Sizilien und Kalabrien, die an dem von circa 400 Bischöfen besuchten Vierten Laterankonzil teilnahmen ${ }^{202}$, stammte die Hälfte aus Sizilien, unter ihnen alle drei Erzbischö$\mathrm{fe}^{203}$. Damit hatten die sizilischen Bischöfe ihre 1179 geübte Zurückhaltung

19773 Bischöfe nennt Ian Stuart RoBInSON: The Papacy 1073-1198. Continuity and Innovation, Cambridge u. a. 1990 (Cambridge Medieval Textbooks), S. 393; 72 erscheinen bei TANGL (wie Anm. 196) S. 213.

198 Allgemein TANGL (wie Anm. 196) S. 221; die Teilnahme der drei Erzbischöfe Nikolaus von Messina, Thomas von Reggio Calabria und Ruffus von Cosenza ist durch Mansi 22, Sp. 215 u. 462 belegt. Vgl. dazu auch KAMP: Kirche (wie Anm. 10) Bd. 2 S. 831 u. 917.

199 Siehe oben bei Anm. 91. Auch die Anwesenheit Guidos von Cefalù ist durch Mansi 22, Sp. 215 u. 462 zu erschließen, vgl. auch KAMP: Kirche (wie Anm. 10) Bd. 3 S. 1048.

200 Es handelt sich um die Bischöfe Anselm von Mileto, Peregrinus von Umbriatico, Guido von Nicastro, Caradon von Tropea, Philipp grecus von Crotone und Irenus von Strongoli. Neben Mansi 22, Sp. 215 u. 462 vgl. auch KAMP: Kirche (wie Anm. 10) Bd. 2 S. 817, 911, 975 Anm. 8, S. 997, 956 u. 908 Anm. 4. Im Falle von Irenus von Strongoli ist die Nennung in Mansi 22, Sp. 215 u. 462 der einzige Nachweis für die Existenz von Irenus.

201 So bereits Tangl (wie Anm. 196) S. 229.

$202 \mathrm{Zu}$ den Zahlen der Teilnehmer vgl. TANGL (wie Anm. 196) S. 229; Neben den genannten 400 Bischöfen ist noch mit 800 sonstigen Klerikern zu rechnen. Hinzu kommt noch die Begleitung der Prälaten, so dass MALECZEK: Mittelpunkt (wie Anm. 141) S. 95, von 5000 Personen als Untergrenze ausgeht, die sich zum Vierten Laterankonzil in Rom einfanden.

203 Nach Kirchenprovinzen und Diözesen geordnet waren dies aus Sizilien die folgenden sieben beziehungsweise acht Bischöfe - mit dem Verweis auf KAMP: Kirche (wie Anm. 10) in Klammern: Ebf. Berardus von Messina (Bd. 3 S. 1021), Bf. Johannes von Cicula von Cefalù (Bd. 3 S. 1054), Ebf. Berardus de Castanea von Palermo (Bd. 3 S. 1131), Ebf. Carus von Monreale (Bd. 3 S. 1194), Bf. Walter von Palearia von Catania (Bd. 3 S. 1213), Bf. Bartholomäus von Siracusa (Bd. 3 S 1239) sowie der namentlich nicht bekannte Bf. von Mazara (Bd. 3 S. 1176 Anm. 31). Unklar ist die Teilnahme von Bf. Anselm von Patti (Bd. 3 S. 1083). Aus Kalabrien waren anwesend: Die 
aufgegeben. Ob dies ein Erfolg der Regentschaft Innozenz' III. war, ist nicht zu belegen, doch dürfte die Regentschaft zu einer Normalisierung der Lage und damit einem verstärkten Besuch des Konzils beigetragen haben. Da Friedrich II. zu diesem Zeitpunkt auf die Unterstützung Innozenz' III. für seine nordalpinen Pläne angewiesen war, könnte sich der königliche Einfluss auf die unteritalienische Kirche nun auch positiv auf den Besuch des Vierten Laterankonzils ausgewirkt haben ${ }^{204}$.

\section{Rechtssammlungen}

Zwar wird man in Zusammenhang mit der Umsetzung des kanonischen Rechtes an die "Collectio Palermitana» denken, die ihren Namen ihrem Aufbewahrungsort im Archiv der Kathedrale von Palermo verdankt. Doch ist nicht klar, wo diese Sammlung entstand und ob sie sich bereits am Ende des 12. Jahrhunderts im Besitz des Kathedralkapitels befand ${ }^{205}$. Liegen insgesamt wenige Rechtssammlungen vor ${ }^{206}$, so scheint auch die Nachfrage nach Rechtsauskünften aus den Regionen Sizilien und Kalabrien gering gewesen zu sein. Denn anders als aus den Regionen des Nordwesten Frankreichs und aus England, kamen aus dem gesamten Königreich Sizilien wesentlich weniger Anfragen an den Papst, die dieser in Form einer Respons beantwortete, welche durch den Eingang in eine Dekretalensammlung in das kanonische Recht Eingang gefunden hätten. Von den circa 470 Dekretalen Alexanders III. gingen

beiden Ebf. Dionysius von Santa Severina (Bd. 2 S. 855) und Girald von Reggio Calabria (Bd. 2 S. 925) sowie die Bischöfe Bernardus von Belcastro (Bd. 2 S. 894) und Johannes von Tropea (Bd. 2 S. 999). Namentlich nicht bekannt sind die fünf Bischöfe von Isola di capo Rizzuto (Bd. 2 S. 905), San Leone (Bd. 2 S. 907), Bisignano (Bd. 2 S. 811), Gerace (Bd. 2 S. 967) und Nicastro (Bd. 2 S. 975)

204 So TANGL (wie Anm. 196) S. 229, die davon ausgeht, dass Friedrich II. die Bischöfe Siziliens zur Teilnahme am Laterankonzil drängte.

205 Zur «Collectio Palermitana» vgl. Lotte KÉRY: Canonical Collections of the Early Middle Ages (ca. 400-1140): A Bibliographical Guide to the Manuscripts and Literature, Washington, D.C. 1999 (History of Medieval Canon Law 1), S. 277, dort weitere Literatur. Die Handschrift, Palermo, Archivio della Cattedrale, 14, entstand offenbar im 12. Jahrhundert in Frankreich und enthält neben der Abbreviatio Ansegisi et Benedicti Levitae (fol. 71r-112v.) auch die Collectio CCCXLII capitulorum (fol., 118r-128r), vgl. auch Jacqueline RAMBAUD-BUHOT: Un corpus inédit de droit canonique de la réforme Carolingienne à la réforme Grégorienne, in: Humanisme actif. Mélanges d'art et de literature offerts à Julien Cain, 2 Bde., Paris 1968, hier Bd. 1 S. 271-281, S. $273-$ 275.

206 Eine systematische Untersuchung der kanonistischen Handschriften süditalienischer Provenienz, die über Montecassino und Benevent hinaus geht, steht noch aus. Zu diesen beiden Zentren vgl. etwa die nun gesammelt vorliegenden Beiträge von Roger Edward REYNOLDS: Studies on medieval liturgical and legal manuscripts from Spain and Italy, Aldershot u. a. 2009 (Variorum Collected Studies Series 927). 
lediglich etwa 30 in das gesamte Königreich Sizilien, während nach England über 150 gingen $^{207}$. Trotz der geringen räumlichen Distanz erweisen sich sowohl Sizilien als auch Kalabrien in dieser Hinsicht als romferne Regionen ${ }^{208}$. Die Insel wirkt hier noch ferner als Kalabrien. Denn für Kalabrien lassen sich bis 1198 immerhin vier klassische Reskripte fassen, ebenso viele wie für das Jahrzehnt danach ${ }^{209}$. Doch aus Sizilien sind keine Anfragen überliefert, die eine Rechtsauskunft zur Folge gehabt hätten. Auffallend ist auf der Insel jedoch das 1198 einsetzende Bemühen der Bischöfe, ihre Handlungen hinsichtlich entfremdeter Güter in Rom absegnen zu lassen ${ }^{210}$. Doch dies dürfte weniger auf eine gesteigerte Romorientierung der sizilischen Bischöfe zurückzuführen sein, als vielmehr auf die Rolle Innozenz' III. als Vormund für Friedrich II. Denn die starke Konkurrenz der königlichen und kirchlichen Gerichtsbarkeit wie auch der königlichen und päpstlichen Gesetzgebungstätigkeit fand mit dem Pontifikat Innozenz' III. noch nicht ihr Ende. Es ist kein Zufall, dass der «Liber Extra» in etwa zur selben Zeit abgefasst wurde wie die Konstitutionen von Melfi ${ }^{211}$.

207 So PaCAut (wie Anm. 47) S. 51. Vgl. zum Zusammenhang zwischen der Verschickung von Dekretalen in Regionen und der Entstehung von Dekretalensammlungen in denselben am Beispiel des Reiches nördlich der Alpen während des Alexandrinischen Schismas Gisela DrossBaCH: Die Entwicklung des Kirchenrechts als raumübergreifendes Kommunikationsmodell im 12. Jahrhundert, in: Zentrum und Netzwerk. Kirchliche Kommunikationen und Raumstrukturen im Mittelalter, hg. v. Gisela Drossbach/Hans-Joachim ScHмidT, Berlin u. a. 2008 (Scrinium Friburgense 22), S. 41-61.

208 Für diese Distanz spricht auch die Zahl der aus den Dekretalensammlungen herauszudestillierenden Urkunden. Für Italien sind dies insgesamt 230 Stücke für das 12. Jahrhundert, von denen jedoch lediglich die in Anm. 209 genannten vier Stücke auf Kalabrien und Sizilien verweisen. Auch in dieser Hinsicht erweisen sich beide Regionen damit als Fernregionen. Zur Zahl der 230 ,italienischen Dekretalen“ vgl. Walther HOLtZMANN: Kanonistische Ergänzungen zur Italia pontificia, Tübingen 1959, S. $67 \mathrm{f}$.

209 Vor 1198 wurden ausgestellt: IP 10 S. 112 Nr. *6 (Paschalis II.), S. 114 Nr. 9 u. 10 (Alexander III.) und S. 106 Nr. 2 (Cölestin III.). Aus den Registern Innozenz' III. stammen die Belege Reg. Inn. III., I/307, I/524, II/139 u. II/251.

210 Vgl. dazu Reg. Inn. III., I/180, I/250 u. I/294. Erstaunlicherweise lassen sich nach dem ersten Pontifikatsjahr Innozenz' III. derartige Anfragen in den Registern nicht mehr fassen.

211 Martin BeRTRAM: Gregorio IX, Innocenzo IV e Federico II. Tre legislatori a confronto, in: „,... colendo iustitiam et iura condendo ..." Federico II legislatore del Regno di Sicilia nell'Europa del Duecento. Atti del convegno internazionale di studi organizzato dall'Universita degli Studi di Messina, Istituto di Storia del Diritto e delle Istituzioni Messina-Reggio, Calabria 20-24 gennaio 1995, hg. v. Andrea Romano, Roma 1997 (Atti di convegni. Comitato Nazionale per le Celebrazioni dell'VIII Centenario della Nascita di Federico II 1), S. 11-27. Die Konstitutionen von Melfi stehen jedoch nicht allein, denn auch andere große Gesetzeskodifikationen entstehen noch im 13. Jahrhundert, jedoch nach den Konstitutionen von Melfi. Vgl. etwa die 1265 abgeschlossenen und unter Alfons X. von Kastilien-León ausgearbeiteten «Siete Partidas». Zur Gleich- 


\section{Ergebnisse}

Anders als erwartet stellt das Epochenjahr 1198 trotz der veränderten Überlieferungssituation und der Vormundschaftsregierung Innozenz' III. für den minderjährigen Friedrich II. im Verhalten der Urkundenempfänger keinen tieferen Einschnitt dar. Zwar lässt sich durch die Registerüberlieferung nun das päpstliche Wollen stärker fassen als zuvor, doch blickt man auf die von Rom ausgestellten Privilegien, so ergibt sich eine erstaunliche Konstanz im Verhalten der Ortskirchen auf Sizilien und in Kalabrien. In beiden Regionen kommt es nicht $\mathrm{zu}$ einer kontinuierlichen Verdichtung der Kommunikation zwischen den Einzelkirchen und dem Papsttum. Denn die Verwerfungen zwischen Roger II. und Calixt II. bilden einen Bruch in der Kommunikation der Ortskirchen mit Rom. Verglichen mit dem restlichen Regno vollzog sich der Bruch in diesen beiden Regionen damit früher als in den anderen Regionen, wo die 40er Jahre den Tiefpunkt des Austausches zwischen Rom und unteritalienischen Kirchen darstellen ${ }^{212}$. Gerade im Vergleich zu den anderen Regionen des unteritalienischen Herrschaftsraumes wird die dominante Rolle des Hauteville für die Kommunikation der Ortskirchen auf Sizilien und in Kalabrien mit Rom deutlich.

Dieser Bruch - gleichsam eine Unterbrechung der scheinbar so teleologischen Entwicklung einer zunehmenden Verdichtung der Beziehungen zwischen Rom einerseits und Kalabrien sowie Sizilien andererseits - macht sich auch bei den Reisen und Legationen bemerkbar, wobei der Blick über die Epochengrenze von 1198 sich als fruchtbar erwiesen hat. Für die Zeit bis 1198 ist für Sizilien sowohl hinsichtlich der Papstreisen als auch von Legationen, die nicht nur politischer Natur waren, Fehlanzeige zu erstatten. In Kalabrien bildet erneut der Bruch mit Calixt II. den Einschnitt - das Instrument der Legationen konnten die Päpste in Kalabrien danach offenbar nicht mehr einsetzen, so dass ab diesem Zeitpunkt Kalabrien wie zuvor bereits Sizilien keine Legaten mehr sah. Das änderte sich jedoch deutlich nach 1198 - was das Fehlen der Legationen in der Zeit zuvor umso sprechender macht. Die massive Präsenz päpstlicher Legaten auf der Insel Sizilien nach 1198 hatte allem Anschein nach vor allem durch die Vormundschaft Innozenz' III. politische Hintergründe ${ }^{213}$.

Sehr ähnlich ist der Befund auch bei der Anwendung der Delegationsgerichtsbarkeit sowie der personellen Austauschprozesse zwischen Rom und den Regionen. Beide Male erweist sich Sizilien als noch distanzierter von Rom, wobei das Ende des Austausches bereits am Ende des 11. Jahrhunderts festzu-

zeitigkeit umfangreicher Rechtskodifikationen im 13. Jahrhunderts vgl. auch den knappen Überblick bei Gabriela SIGNIORI: Das 13. Jahrhundert. Einführung in die Geschichte des spätmittelalterlichen Europas, Stuttgart 2007, S. 123-129.

212 KAMP: Episkopat (wie Anm. 25) S. 117f.

213 Die kirchlichen Handlungen der Legaten sind leider noch nicht in gleicher Intensität wie ihre politische Tätigkeit aufgearbeitet. 
machen ist. Auch nach 1198 ändert sich zumindest im Episkopat in dieser Hinsicht nichts. Beachtenswert für die Fragestellung des Netzwerkes nach Instrumenten, die gleichsam in einer Region erprobt und dann auf andere übertragen wurden, ist die Erhebung von Kardinälen zu Bischöfen der unteritalienischen Kirche - bereits ab dem ausgehenden 11. Jahrhundert. Zwar wurde dieses Instrument, mit dessen Hilfe Regionen auch als Interessensräume beschrieben werden können, in Kalabrien und Sizilien nicht eingesetzt, doch kam es in Unteritalien vor allem in einer Zeit zum Einsatz, in der die unteritalienische Kirche für die Päpste offenbar eine große Bedeutung einnahm, was spätestens im letzten Drittel des 12. Jahrhunderts für Oberitalien galt.

So sehr die beiden Regionen sich in ihrem so skizzierten grundsätzlichen Verhalten Rom gegenüber ähneln, so treten doch bei einer Differenzierung der Inhalte deutliche Unterschiede zutage, so bei Papstschutz, Exemtionen, Weihen und Palliumprivilegien. Der Papstschutz fand auf Sizilien praktisch erst seit Alexander III. Anwendung - wobei die geringe Anzahl der Klöster erstaunt, die mit dem Papstschutz bedacht wurden, oder aus der entgegengesetzten Perspektive formuliert: nach diesem nachsuchten. In Kalabrien sind hingegen mehrere Papstschutzverleihungen seit dem Beginn des 12. Jahrhunderts nachzuweisen. Diese Region stellt sich damit als offen für den Papstschutz dar. Das gilt auch für die Exemtionen, wobei hier ein Nachwirken der griechischen Prägung die Ursache für ein vermehrtes Bemühen um Exemtionen sein könnte. Doch in etlichen Fällen dürfte vor allem die dominante Stellung des Herrschers und dessen besondere Bindung an eine kirchliche Institution für die Exemtion ausschlaggebend gewesen sein, so dass sich Exemtion und Papstschutz in einigen Bereichen als päpstliche Befestigung des von herrscherlicher Seite hergestellten status quo gedeutet werden können ${ }^{214}$. Unterschiede zwischen den beiden Regionen ergeben sich auch bei den Weihen. Zwar forderte Alexander III. ein weitgehendes Weihevorrecht für den Papst gegenüber den Bischöfen Siziliens ein, doch steht dieses Ansinnen in starkem Kontrast zur Ausformulierung dieses Vorrechtes in den Papsturkunden für sizilische Empfänger, denn in den konkreten Urkunden für sizilische Bischöfe findet sich dieses Weihegebot nicht - im Gegensatz zu den kalabrischen Urkunden. Zudem sind Weiheregelungen für Sizilien bis auf eine Ausnahme allein für Bischöfe zu fassen, während in Kalabrien auch Klöster um eine Weihe des Abtes durch den Papst bemüht waren, im Falle von S. Maria Mattina fertigte man dafür sogar eine Fälschung an. In besonderem Maße kommt der Unterschied zwischen den beiden Regionen bei den Palliumprivilegien zum Ausdruck: Für Kalabrien ist lediglich ein einziges Palliumprivileg überliefert, das 15 Stücken für sizilische Bischöfe gegenübersteht. Der unterschiedliche Befund dürfte durch eine schärfere Konkurrenz der sizilischen Bischöfe untereinander bedingt sein, bei der auch liturgische Vorrechte ein Mittel der Auseinanderset-

214 Zu ähnlichen Phänomenen im Reich nördlich der Alpen vor der Mitte des 11. Jahrhunderts JOHRENDT: Papsttum (wie Anm. 97) S. 214f. u. $218 f$. 
zung sein konnten. Nicht zuletzt die beiden Infulprivilegien für das Kloster Monreale und den Abt des Klosters S. Giovanni eremita in Palermo weisen auch in diese Richtung ${ }^{215}$. Die offene und daher Konkurrenz fördernde Situation auf der Insel Sizilien ist durch die stetig veränderte Kirchenorganisation der Region zu erklären, sowie seit Roger II. die intensivere Bindung der sizilischen Bischöfe an den königlichen Hof, wo sie untereinander in Konkurrenz traten. In dieser Situation war jedwede Absicherung und zeremonielle Demonstration der eigenen Stellung für die Bischöfe und ihre Kirchen geradezu lebensnotwendig. Wie labil die Lage war, musste etwa auch Erzbischof Bartholomäus von Palermo erfahren, den Wilhelm II. - als sich der Erzbischof seinem Plan der Erhebung Monreales zum Erzbistum entgegenstellt - aus dessen Erzbistum verbannte ${ }^{216}$.

Die starke Fixierung der Kirchen Siziliens und Kalabriens auf den König mochte vor allem durch die Erfahrungen des Anakletianischen Schismas noch weiter verstärkt worden $\operatorname{sein}^{217}$. Das führte auch dazu, dass die Konkurrenz Rom die Tür nicht allzu sehr öffnete, um einen maßgeblichen Einfluss auf die Kirche vor allem der Insel Siziliens aber auch Kalabriens zu gewinnen. Dazu mochte auch beigetragen haben, dass der personelle Austausch zwischen den Regionen und der Kurie zumal nach der Wende zum 12. Jahrhundert auf der Ebene der Bischöfe praktisch nicht vorhanden war. Das betrifft nicht nur die Herkunft der Bischöfe, sondern in groben Zügen ebenso deren Besuch der päpstlichen Synoden. Und bis zum Vierten Laterankonzil ist hier besonders von den sizilischen Bischöfen eine reservierte Haltung festzustellen. Denn stellten die unteritalienischen Bischöfe auf dem Dritten Laterankonzil immerhin fast ein Viertel der etwa 300 teilnehmenden Bischöfe, so kamen nur zwei von der Insel Sizilien. Erst 1215 veränderte sich die Situation.

215 IP 10 S. 275 Nr. 2 u. 243 Nr. *1.

216 Vgl. KamP: Kirche (wie Anm. 10) Bd. 3 S. 1120. Auch dies offenbart den hohen Einfluss des sizilischen Herrschers bis in den Bereich der Kirchenorganisation hinein. Den ottonischen Herrschern war es nicht möglich gewesen, den Widerspruch eines Bischofs gegen ihre Bistumspläne durch dessen Vertreibung aus der Welt zu schaffen, vgl. dazu Ernst-Dieter HEHL: Der widerspenstige Bischof. Bischöfliche Zustimmung und bischöflicher Protest in der ottonischen Reichskirche, in: Herrschaftsrepräsentation im ottonischen Sachsen, hg. v. Gerd Althoff/Ernst Schubert, Sigmaringen 1998 (VuF 46), S. 295-344.

217 KAMP: Episkopat (wie Anm. 25) S. 129: „Die Bischöfe, auch diejenigen offenbar, die sich nur zögernd unter das Joch der neuen Monarchie gebeugt hatten, gewannen in der Zeit Rogers II. einen Erfahrungshorizont, der sie auf Distanz zur römischen Kurie und den dort tonangebenden geistlichen Kräften gehen ließ, wenn ihre staatliche Loyalität angesprochen war." Diese Erfahrung spiegelt sich auch bei der Bitte um Urkunden von Seiten der Ortskirchen gegenïber Alexander III. wider, obwohl Wilhelm II. eine der wesentlichen Stützen dieses Papstes war, vgl. dazu Jochen Johrendt: Cum universo clero ac populo eis subiecto, id ipsum eodem modo fecerunt. Die Anerkennung Alexanders III. in Italien aus der Perspektive der Papsturkundenempfänger, in: QFIAB 84 (2004) S. 38-68, hier S. 55f., 62 u. $66 f$. 
Die Erklärung für die mangelnde Attraktivität Roms für die Bischöfe Siziliens und Kalabriens lag in einer effizienten Alternative, welche das normannische Königtum in vielerlei Hinsicht bot. Vor allem durch das gut organisierte Gerichtswesen ist es zu erklären, dass sich nur eine Hand voll Delegationen in diesen Regionen nachweisen lassen, auch nach 1198. Die Appellation an den König war offenbar effektiver, zumal ihm zur Umsetzung des Urteils auch durchschlagskräftigere Mittel zur Verfügung standen ${ }^{218}$. Dies erklärt wohl auch die mangelnde Überlieferung kanonistischer Sammlungen aus dem unteritalienischen Raum. Ein dialogisches Miteinander von Ortskirchen und Kurie, in dem Rechtsfragen gestellt, beantwortet und auf diese Weise Rechtsauffassungen gemeinsam weiterentwickelt und homogenisiert wurden, fehlte hier.

In Kalabrien und Sizilien ergab sich somit eine unterschiedliche Funktion, welche den Päpsten durch die Ortskirchen zugewiesen wurde. Und der Raum, der ihnen dazu blieb, wurde selbst am Ende des 12. Jahrhunderts immer noch maßgeblich durch das Königtum bestimmt. Beide Regionen demonstrieren, dass die Zentralisierung der Kirche keine teleologische Entwicklung war. Zugleich bestand - abgesehen für die Zeit des anakletianischen Schismas - für die Päpste kein Zweifel an der Romtreue des unteritalienischen Episkopates, auch wenn die daraus resultierenden Handlungsmuster nicht auf einen intensiven Austausch zwischen der Kurie und den beiden Regionen hindeuten. Die Folgen der Romorientierung blieben - verglichen mit anderen Regionen Europas - auf einer relativ oberflächlichen Ebene, durchdrangen die Kirche nicht sehr tief. Und sie hinderte die Hirten Siziliens und Kalabriens nicht daran, sich im Falle eines möglichen Konfliktes klar auf die Seite der Normannenherrscher zu stellen - aller Romorientierung zum Trotz ${ }^{219}$.

$218 \mathrm{Vgl}$. allgemein zur Stellung des Königs als Schutzherr für die unteritalienische Kirche Loud: Latin Church (wie Anm. 5) S. 286-306.

219 Vgl. KAMP: Episkopat (wie Anm. 25) S. 129. 
